\title{
Laser-Induced Breakdown Spectroscopy
}

\author{
Taesam Kim and Chhiu-Tsu Lin
}

Additional information is available at the end of the chapter

http://dx.doi.org/10.5772/48281

\section{Introduction}

Laser-induced breakdown spectroscopy (LIBS) is an atomic emission spectroscopy. Atoms are excited from the lower energy level to high energy level when they are in the high energy status. The conventional excitation energy source can be a hot flame, light or high temperature plasma. The excited energy that holds the atom at the higher energy level will be released and the atom returns to its ground state eventually. The released energy is welldefined for the specific excited atom, and this characteristic process utilizes emission spectroscopy for the analytical method. LIBS employs the laser pulse to atomize the sample and leads to atomic emission. Compared to the conventional flame emission spectroscopy, LIBS atomizes only the small portion of the sample by the focused laser pulse, which makes a tiny spark on the sample. Because of the short-life of the spark emission, capturing the instant light is a major skill to collect sufficient intensity of the emitting species. Three major parts of the LIBS system are a pulse laser, sample, and spectrometer. Control system is usually needed to manage timing and the spectrum capturing. Figure 1 illustrates those three major components and a computer in the conventional LIBS.

The LIBS has been used for the materials detection and analysis in various applications, such as steel and alloys[1-8], paints and coatings[9-15], wood pre-treatment[16], polymers [17], bacteria[18], molds, pollens, and proteins[19,20], and space exploration[21]. The great majority of LIBS results were consolidated in the reviews[22] and books[23, 24].

In spite of its advantage in analytical spectroscopy, LIBS application is still restricted within certain areas and propagation of the technology is not very wide. Many laboratory LIBS systems are built in schools, research labs and companies with discrete optical parts. Their pioneering approach in the new application seemed promising for a certain samples, but actual use in the application field is usually very limited. We can explain the situation with other analytical techniques, for example, Gas Chromatography (GC). The GC can separate the volatile species. However, one GC setup can work for a narrow range of species grouped in the sample. For different applications, the user must change the GC column, detector, 


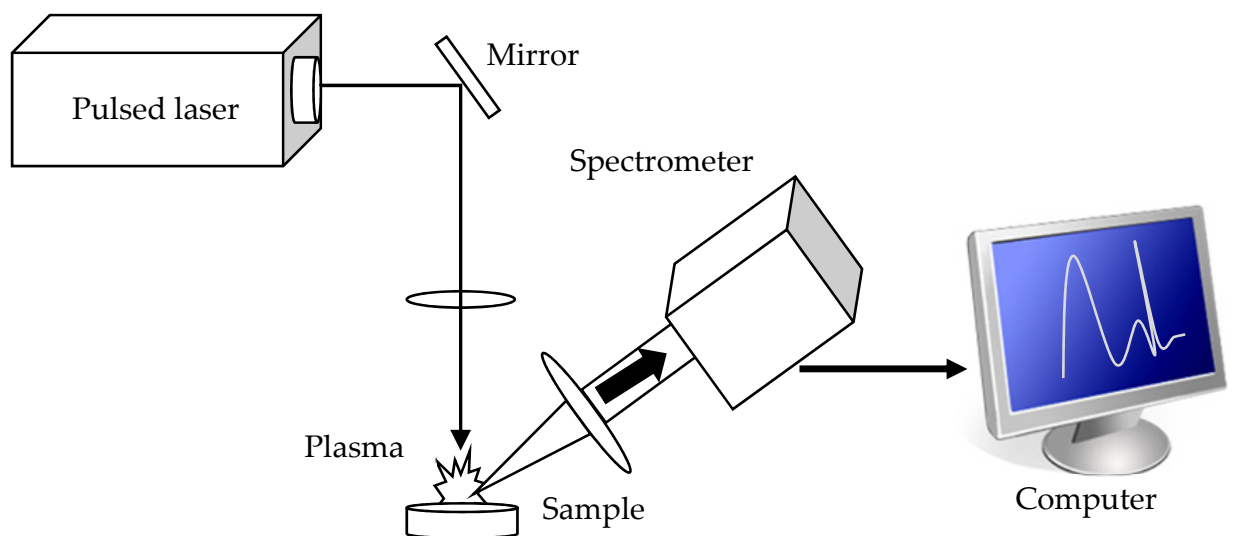

Figure 1. The conventional LIBS system configuration

carrier gas or at least use a new column temperature cycle. The application of LIBS also needs case-by-case adjustment. Many new applications start with looking at the advantages of LIBS and choosing a LIBS setup, and it still needs a detailed investigation for successful analysis.

This chapter describes how the LIBS system works and explains the major parts of LIBS to select specific functional requirements for its intended application. The three major parts: laser, sample and spectrometer are explained. The laser provides the breakdown energy and plasma generation. Analytical sample is the target of the laser shot and the source of emission species. The spectrometer comprises detection system with light detector and computer. Their disadvantages and limitations are discussed then suggesting how to select the equipment type and configuration to maximize the advantages of LIBS. This will provide a beginning inspiration of LIBS systems to install and apply the desired specific analytical purpose or application area.

\section{LIBS system design with modern technology}

a. Laser as a breakdown energy source

LIBS uses pulsed-laser light and focuses it onto the sample surface to make a plasma plume that contains the highly excited species of the sample composition. For generating plasma, there is a threshold value of the energy density. The threshold level will depend on the absorption coefficient of the sample surface of the laser wavelength, which is highly different by the sample phase. Gas and liquid need more energy to make breakdown. Solids with a dark color surface easily make a strong breakdown compared to clear or highly reflective solids. Figure 2 shows the effect of laser energy to make breakdown by the relation of laser power and focusing. Starting with a laser beam as $1 \mathrm{~cm}$ diameter, this light beam can be condensed by a convex lens. The focused beam density becomes $160 \mathrm{~J} / \mathrm{cm}^{2}$ as in Figure 2(a). Also, the laser is operating in the pulsed mode, assuming a10 nsec duration, total power per unit of time will be $16 \mathrm{GWatt} / \mathrm{cm}^{2}$ as 


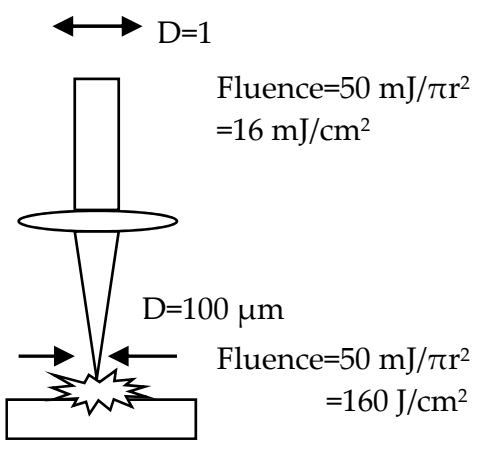

(a)

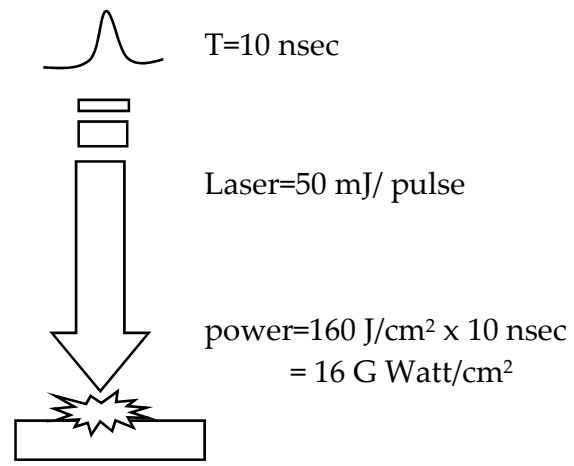

(b)

Figure 2. Laser energy delivery for breakdown condition. (a) focusing effect, (b) pulsing effect

in Figure. 2(b). Most of breakdown needs a few GW (106 Watt) of energy density, indicating that $50 \mathrm{~mJ}$ of laser energy is sufficient to make breakdown and evaporate most of material.

At the early stage of LIBS development, several types of pulse laser were used to make laser-induced breakdown plasma. An eximer laser was an important pulse laser especially for the UV light pulse. XeCl-eximer with $308 \mathrm{~nm}$ was used in the LIBS to measure elemental distribution on the paper coating[25]. The laser energy of $0.2 \mathrm{~mJ}$ was focused and made a crater of $30 \mu \mathrm{m}$ diameter. This energy is corresponding to $10^{8} \mathrm{~W} / \mathrm{cm}^{2}$. More than $90 \%$ of ingredients in the paper coating are pigment, binder and other agents. The pigment's main component is usually aluminum oxide, silicon dioxide and calcium carbonate. The mass of coating material ablated by single laser pulse was estimated to be about $2 \mathrm{ng}$ by a laser shot. A typical nitrogen laser has a wavelength $337.1 \mathrm{~nm}$ and a pulse duration of $10 \mathrm{nsec}$. Just like the eximer laser, the nitrogen laser LIBS configuration in Figure. 3 also includes discharge from the wide shape of the electrode. The laser beam is usually a few $\mathrm{cm}$ wide, so a tight focusing is needed. The surface of solar cell was measured by nitrogen laser breakdown and only a $40-\mathrm{nm}$-thick $\mathrm{TiO}_{2}$ layer was detected[26]. The very popular pulse laser is Nd:YAG laser because it has a solid laser oscillator in a small size and light weight. The fundamental wavelength is $1064 \mathrm{~nm}$ with a pulse duration of $10 \mathrm{nsec}$ typically. The Nd:YAG laser does not require any gas supply. The laser model for LIBS size usually has a closed loop water cooling that excludes external connection. A typical LIBS setup was shown in an earlier paper[27] as in Figure 4. A $50 \mathrm{~mm}$ focal length convex lens makes a simple optics configuration to make plasma on the sample.

b. Optical arrangement for laser-induced breakdown spectroscopy

When a laser shoots on the sample surface, a plasma plume arises from the inner to the outer surface. The actual size of plasma plume made by a $100 \mathrm{~mJ}$ laser pulse will be few millimeters. During the plasma propagation from the sample surface, the time profile features can be observed. The very initial emission is generated at the bottom of the plasma 


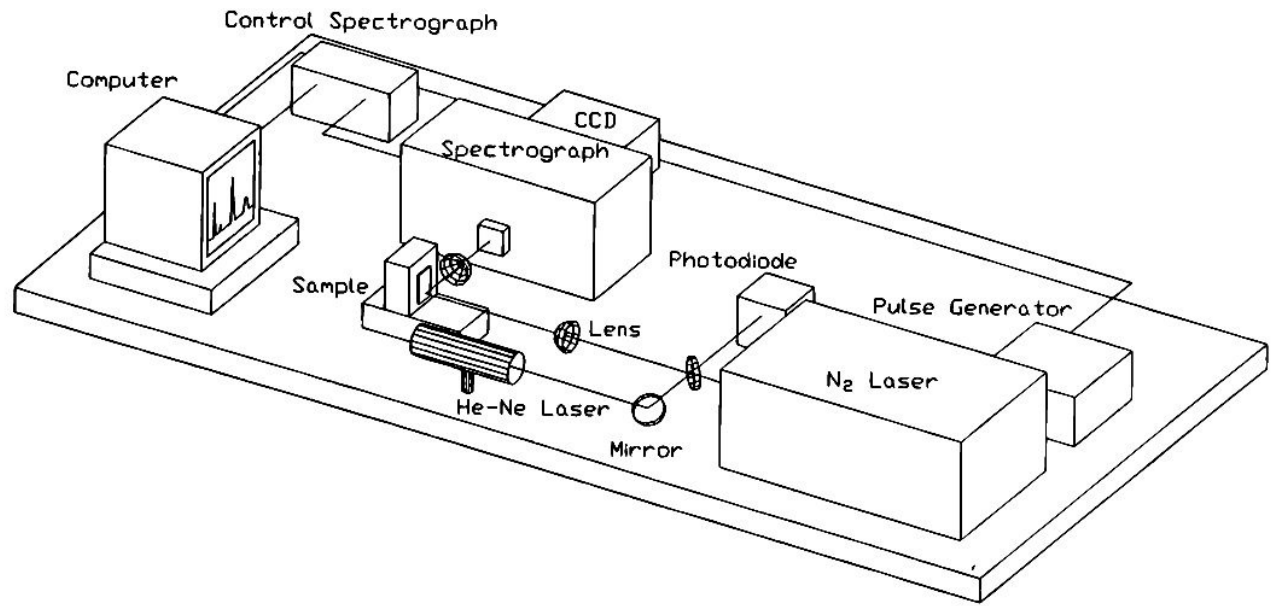

Figure 3. A LIBS setup with nitrogen laser.

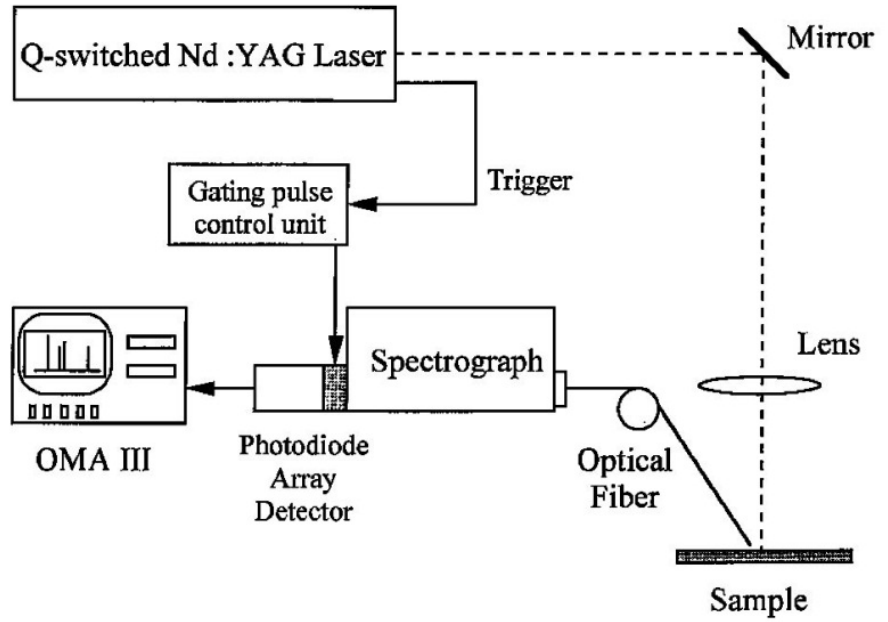

Figure 4. Schematic diagram of the LIBS setup with ND:YAG laser

plume, and then expanded to the outer plume. Depending on the light collecting optics, plasma propagation is captured at the different time. At the initial LIBS design uses a sideview emission collection as in the Figure. 5 (a). The angle between the laser light path and the collecting optic can be any angle, but is typically 30-45 degrees. Some experiments use 90 degrees, which is a complete side view of the plasma and will lose some portion of emission by the shadow of the sample itself. This configuration is occasionally used for plasma physics study. The collateral view design Figure. 5 (b) is a useful optical configuration for 
non-fixed sample distances. Laser light path shares emission collection optics. A selective wavelength reflector or prism can be used to separate laser light and emission through the light path. This design has several optical parts and needs complicated adjustments for optimum light measurement. The collateral configuration has many advantages. Collecting optics looks at the plasma in front of the plasma (or top of the plasma)at every point in the light axis and in the focus cone, which means they capture every light emitting species during plasma propagation to the space. Because some elements have different propagation profile than others, propagation height changes the signal significantly at the angled collection. The next advantage is that the optical part can be integrated in the compact enclosure, and it allows the operator to move the optics (detector head of LIBS) more freely. Remote monitoring LIBS, hand held design LIBS, should be compact and have a mostly collateral optics configuration.

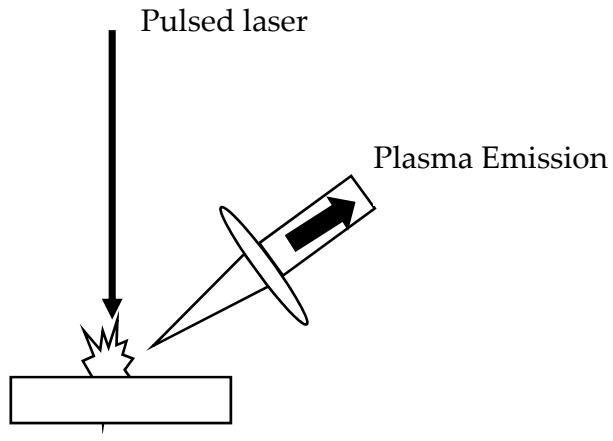

(a)

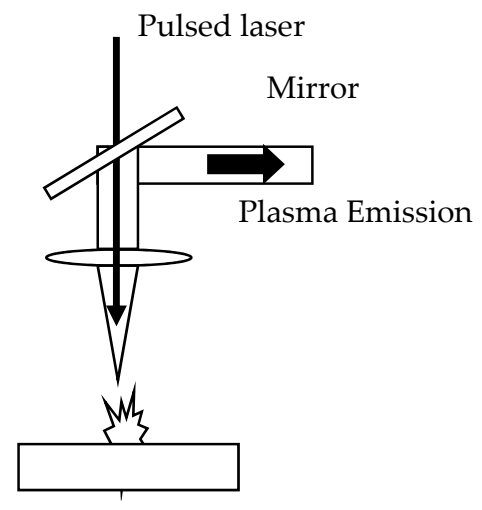

(b)

Figure 5. Side collection and (b) collateral collection configuration of plasma emission

c. Sampling technique

The first mentioned advantage of LIBS has been no-sampling step. In the very beginning review in the Encyclopedia of analytical Chemisstry, Yueh, Singh and Zhang described it as "LIBS uses a very small amount of samples, and no sample preparation is necessary. It has the ability to perform real-time analysis because it prepares and excites the sample in one step". They then consecutively mentioned, "The disadvantage of LIBS is that the plasma conditions vary with the environmental conditions as well as the laser energy fluctuation."We can infer from the description of LIBS that no-sampling is both an advantage and a disadvantage. Most of analytical the techniques need a certain sampling procedure to bring the sample to the technique (or machine). During the sampling procedure, like the acid digestion in the flame analysis, the sample is homogenized and their matrices become concordant. However, if LIBS analyzed the sample without any pretreatment process, then the irregular homogeneity is inevitable. As a result LIBS will include 
severe matrix effects at the real sample. It will mitigate the biggest advantage, i.e., nosample process. In other words, if the sample is measured as it is, the species in same concentration do not make a consistent signal, the analytical result will be severely diverted.

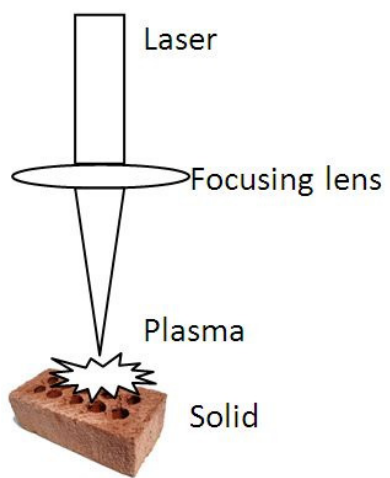

(a)

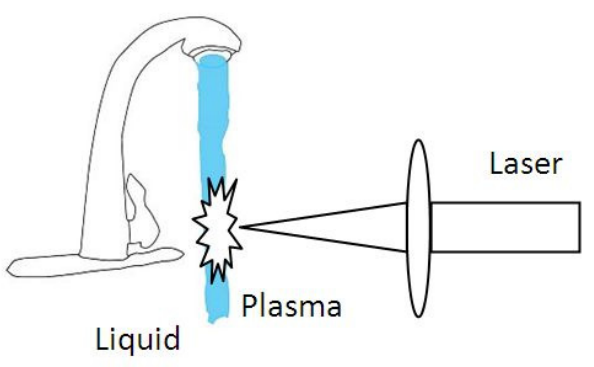

(b)

Figure 6. Solid sample and liquid sample under LIBS measurement

The fluctuation will be more serious because LIBS takes only a small amount of the sample, usually a micron sized spot. Two possible sample types are depicted in the Figure. 6. A solid sample is the most convenient sample type. Metal and ceramic samples include elements with strong atomic and ionic emission. Their emission spectra are measured at the range from UV to visible light, which is feasible by the most spectrometers. The spectra from many elements from the tool steel are shown by the Nd:YAG laser excitation[28]. In this research, the microscopic view of the ablated holes made on tool steel is about 10 microns in diameter. This resolution indicates that any inhomogeneity more than 10 microns will be clearly observed from each laser pulse measurement. The intensity of element-specific spectra provides a simple qualitative analysis. Their method was sufficient to characterize the nature of the defect by a simple estimation of the elemental composition between the basic material and the defect.

\section{d. Capturing emission light}

The LIBS signal is instantaneous and decays quickly. Temporal control of the detecting device is very important. In spite of the fact, overall emission can be captured by opening entire time of the spectrometer, most of LIBS measurement is controlled by time gate operation. Time control improves the signal-to-noise ratio by eliminating the continuum emission. A typical emission profile shown in the Figure 7, recorded at the different heights from the sand/ soil mixture sample[29]. As soon as the laser fires with the duration of a few nsec of pulse width, the plasma intensity is propagating outward from the sample surface. At about $0.5 \mu \mathrm{sec}$, plasma is observed at $0.3 \mathrm{~mm}$ away from the surface. At the propagating distance is $3 \mathrm{~mm}$ at $12 \mu \mathrm{sec}$, then plasma cool down with decreasing intensity until 20- 30 
$\mu$ sec. The plasma size will be much smaller and life is shorter when a weak laser power is used. The experiment uses aluminum[30] with a diode-pumped Nd:YAG laser, which can run at a faster repetition rate $(\mathrm{kHz})$ with a laser energy of $80 \mu \mathrm{J}$, was setup under the microscope excitation and detection optics. Like other flash lamp pumped lasers, the temporal profile of continuum emission is shown in Figure. 8 for aluminum atom ( $\mathrm{Al} 396.1$ $\mathrm{nm}$ ) and aluminum ion ( $\mathrm{Al} \mathrm{II}$ at $358.6 \mathrm{~nm}$ ) emission lines. The laser pulse was fired at the zero time of the $x$ - axis. This profile indicates, the broad band continuum emission, which comes from high temperature heated plasma and regardless of the species in the plasma, has a lifetime of about $13 \mathrm{nsec}$. The ionic line from $\mathrm{Al}$ ion has shorter lifetime about $24 \mathrm{nsec}$. The neutral lines stay much longer, up to $80 \mathrm{nsec}$.
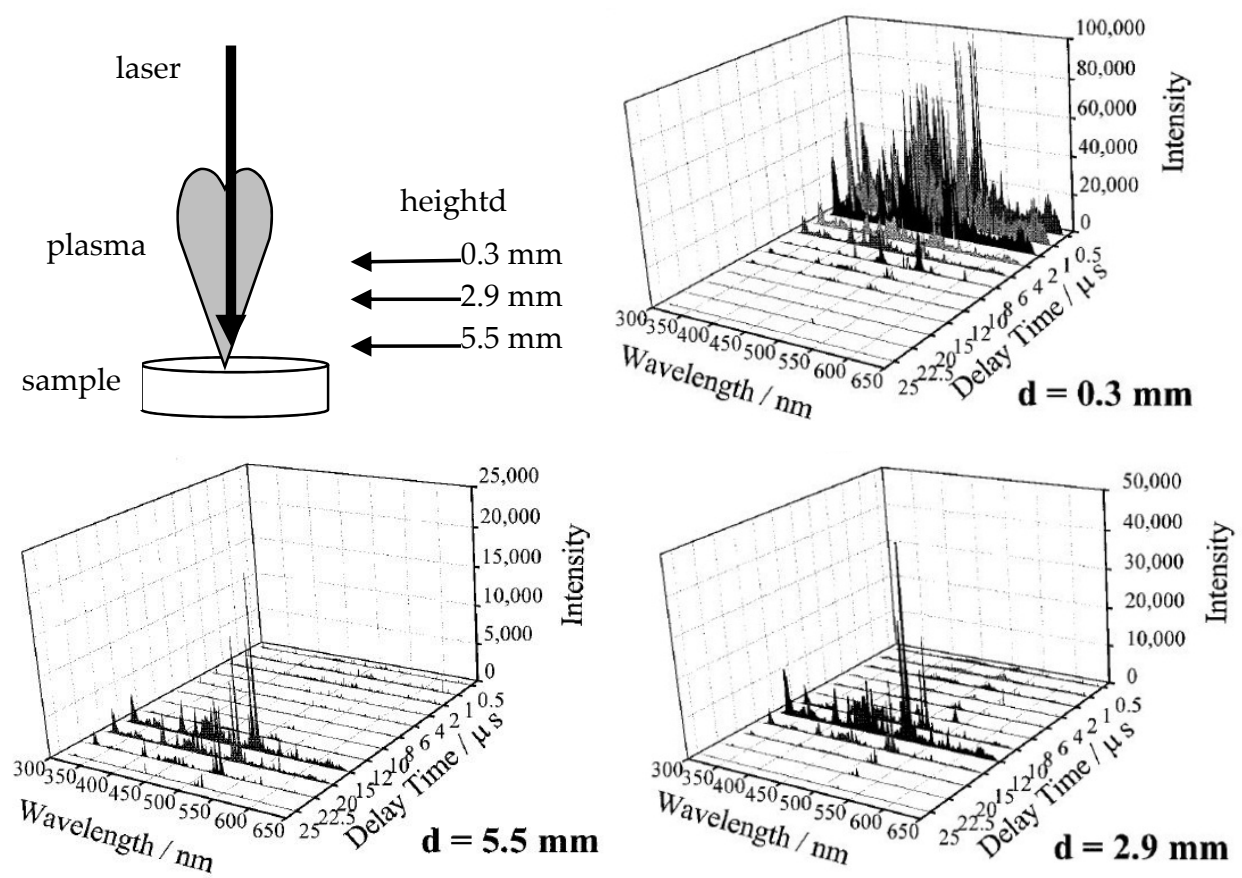

Figure 7. Spectra as a function of decay time measured at three observation distance from the sample surface. The original figure is rearranged to indicate observation height more clearly.

The lifetimes of laser-induced plasma are easily compared at various excitation energies from the silicon sample[25]. The time profile shows the plasma emission signal depends on the excitation pulse energy. Absolute intensity of the signal will increase by increasing laser pulse energy. The decay plot in the Figure 9 is normalized to a maximum intensity for comparison. This research explains the decay time dependence by the excitation energy that the probability of excitation to higher energy level is increased and more populated, leading to a longer decay time. Also, the upper state of the monitored transition receives population from this higher state at later times and lengthening of the rise time of the signal 


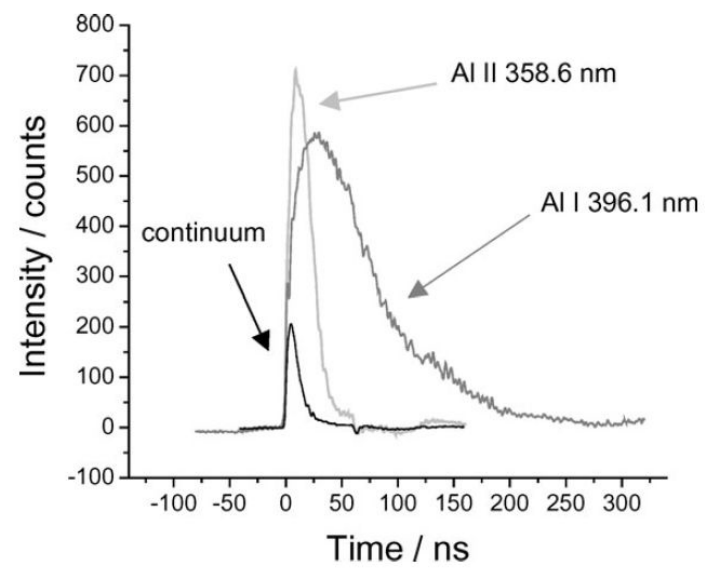

Figure 8. Temporal profile of continuum emission and aluminum (atom and ion) emission.

will result. As a result, the lifetime point of LIBS will be changed by the system setup, especially using laser power. Capturing time of emission signal should be determined empirically by looking at the profile, usually at peak intensity point.

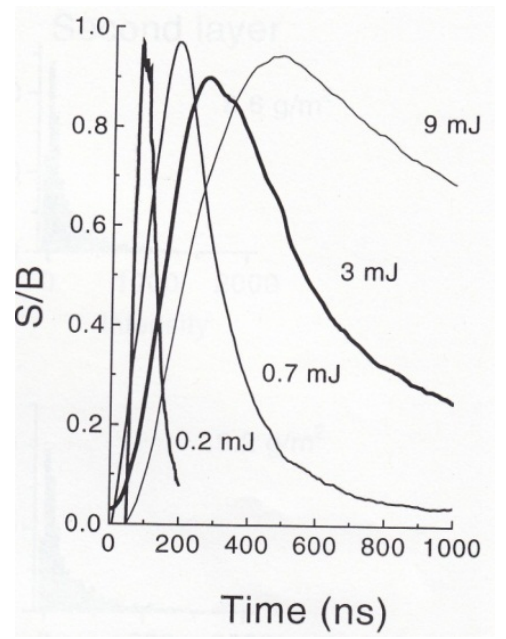

Figure 9. Time resolved signal-to-background ratio of the silicon line at $251 \mathrm{~nm}$ at various excitation energies.

e. Spectrometer and detector

Spectrometer completes the detecting part with a photo sensor and a manipulating computer. The spectrometer must have proper resolution and sensitivity. Also, in many cases the plasma emission needs to be separated from the continuum background signal, the detector has to be operated by timing control or gating operation. Various types of 
spectrometer with CCD array detector are available in the market. The wavelength range needed for LIBS is UV to visible range to have detection of most elements. If the dispersion of the spectrometer is $0.3 \mathrm{~nm}$ to measure $1 \mathrm{~nm}$ peak with three pixel, the pixel to pixel dispersion should be $0.3 \mathrm{~nm}$. Total of 1024 pixel CCD array can have coverage $1024 \times 0.3=$ $307 \mathrm{~nm}$, which can assign the range as $250 \mathrm{~nm}$ to $557 \mathrm{~nm}$ span. In many cases, the sample will have mixed elements and the emission lines will be overlapped and difficult to distinguish with $0.3 \mathrm{~nm}$ resolution. A conventional CCD array detector may not provide sufficient resolution and coverage to measure LIBS.
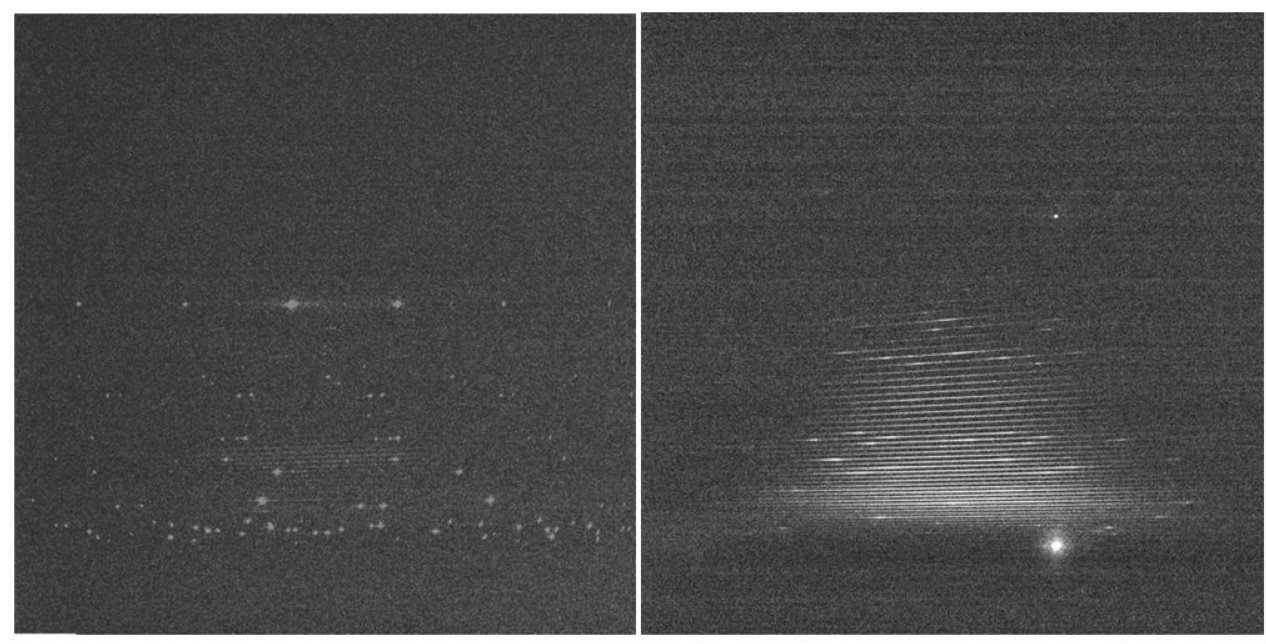

Figure 10. Echelle spectrometer dispersion image (a) Hg lamp, (b) LIBS spectrum of Sn metal

A correction of the array detector resolution is accomplished using multiple stacked spectrometers. For example, 5 spectrometers with 1000 array CCD stacks will cover a 500 $\mathrm{nm}$ span, in which each spectrometer covers a $100 \mathrm{~nm}$ range with $0.1 \mathrm{~nm}$ resolution. Echelle spectrometer uses very high orders of dispersion. One or two prisms are used to separate each diffraction order. As a result, the spectra are dispersed in two dimensional surfaces as shown Figure 10. The CCD detector in the Echelle spectrometer should be a two dimensional, the same as in the image camera. The continuum emission from the spark also engages in the Echelle spectrometer, so the detector must have gated operation. To satisfy those requirements, such as two dimensional, sensitive and gated operation, the cost of CCD detectors for the Echelle spectrometer is still significantly high.

\section{Sample type and their application}

This section illustrates various application examples that have performed from the authors' research group. As we have mentioned in the previous section, the LIBS technique needs individual verification for an application, because it does not need sampling. Three typical applications are explained in this section. 


\section{a. Paint and coating identification}

Materials and techniques of paints and coatings require an appropriate verification process to achieve the desired property of the protective finishing. The organic coating involves a multi-step process in which the quality of the metal finish required for an industrial product would determine the number and the type of steps in a given process[31]. These multi-step coating processes include the selection and composition verification of substrates, surface cleaning, surface pre-treatment, primer, topcoat, and the application of paint curing methods. The paint formulation is a mixture of multi-ingredients, composing: resins, solvents, pigments, fillers, corrosion inhibitors, and other rheological additives. The organic coating in metal finishing practice is extremely complex. The complexities of paint compositions, paint types, and painting processes make their chemical analysis very difficult. In spite of some elemental analysis methods that have been well established for the general purpose in chemistry, the determination of metallic components in paint has been relied on the indirect analytical methods. For example, the metallic zinc dust in the Zn-rich epoxy primer was determined by differential scanning calorimetry (DSC)[32]. The DSC method measured the apparent heat of fusion of the paint sample, and compared this measured value to the standard value of pure zinc as an indirect measurement of zinc composition in paint. Infrared absorption spectroscopy is useful sometimes for the composition analysis if the paint ingredients contain any specific functional groups which are spectroscopically active[33], such as the isocyanate group in the urethane. The direct analysis of these functional groups may be possible only if the paint sample is uncured, and contained a relatively simple composition. In practice, there is no direct way for identifying a cured paint film. Once the paint, e.g. epoxy or urethane, is applied and fully cured, no more epoxy or isocyano functional group would remain in the paint film. Even though, the researchers have attempted to characterize the fully cured paint products by identifying the hydroxyl or amino groups, and use them for differentiating the epoxy paint or urethane paint. The results are generally inconclusive because the majority of other cured paints also have those functional groups as reaction products. The LIBS technique described in this section shows the capability of coating identification at the specimen surface. [34]

\subsection{Materials of paints and coatings}

The substrates selected for spectral fingerprinting by LIBS technique are: (i) aluminum alloys (2024-T3, 3003, 7075-T6 from Advanced Coating Technologies, Inc. (ACT), Hillsdale, $\mathrm{MI})$ and pure aluminum foil (Aldrich Fine Chemicals), and (ii) cold-rolled steel (CRS from Q-PANEL, Cleveland, $\mathrm{OH}$ and Caterpillar's OEM facility) and pure iron (Aldrich). The surface pretreated substrates used for LIBS studies are: (i) Al 2024-T3/Clad, a ultra thin layer of pure aluminum is treated on 2024-T3 aluminum alloy, (ii) Al 2024-T3 Bare/Alodine 1200, the surface of 2024-T3 aluminum alloy is treated with Alodine 1200 solution which contains chromates (i.e., hexavalent chromium), (iii) phosphated (Bonderite 1000, or B-1000) and phosphated/chromated (B-1000/P-60) from ACT, and (iv) galvanized (electroplated and hotdipped) and galvalume steel plates that have a treated surface layer of $\mathrm{Zn}$ and $\mathrm{Zn} / \mathrm{Al}$, respectively. Eleven heavy-machine OEM paint samples (four urethane, three epoxy, and 
four alkyd) were used for the spectral fingerprinting by LIBS technique. The paints were applied on $2 \times 4$ inch steel panels using a spray coating method and cured thermally or by air-dry as directed by the paint manufacturer.

\subsection{LIBS: An in situ and quasi-nondestructive analytical technique}

LIBS technique is capable of carrying out a depth profile analysis of successive surface layers by controlling and calibrating the working parameters of LIBS system. A Q-switched Nd-YAG laser (Continuum, Minilite II) operating at a wavelength of $1064 \mathrm{~nm}$ was employed as the excitation source. The pulse laser has a power of $50 \mathrm{~mJ}$ per pulse and a pulse width of $8 \mathrm{~ns}$. The laser beam was focused onto the sample with a $5 \mathrm{~cm}$ focal length lens. A fiber optic cable collected the breakdown plasma emissions at the sample surface and directed them to a portable, miniature, CCD array fixed-grating spectrometer. Figure 11 shows the optical microscope images of some LIBS-measured sites on a painted steel panel: (a) paint surface before analysis, (b) one laser pulse applied, (c) two laser pulses applied, and (d) five laser pulses applied. The scale bars are $50 \mathrm{~m}$ in length. The first shot of the focused laser beam (70 $\mathrm{mJ} /$ pulse) made a burn pattern on the paint surface (Figure. 11b). The successive laser pulses penetrated into the coating layers and eventually reached the metal substrate (Figure. 11d). In principle, the LIBS spectrum recorded after each laser pulse, or for each layer of the multilayer paint samples, should generate the characteristic breakdown spectral peaks of the corresponding chemical compositions. The affected coating area by the laser pulse is limited to less than $100 \mu \mathrm{m}$ in diameter (Figure. 11b, 11c and 11d). The layer thickness of materials that each laser pulse can penetrate is a function of laser fluent at the focal point, optical geometry and material type. It is important to mention that a well-established elemental analysis method, such as EDX can also perform a similar analysis. However, the sample used in EDX analysis must be cut into a few millimeter sizes for fitting inside the detection stage in a vacuum chamber. Also, the cut samples need to be covered with a conductive coating for EDX analysis because paints are the dielectric materials. This film deposition of conductive layer is again done under another vacuum facility. These complicated sampling processes are eliminated in the LIBS analysis.

\subsection{LIBS characterization of substrates}

A less trivial experiment was performed to determine whether the LIBS system could be used to distinguish between different alloys of the same main metal content or between the same metal alloys obtained from different manufacturing sources. Aluminum has many alloys in common use, and these alloys frequently need specific protective coatings for aerospace applications. The 2024-T3 Al alloy contains copper as the main dopant (i.e., $4.4 \%$ $\mathrm{Cu}, 0.6 \% \mathrm{Mn}$, and $1.5 \% \mathrm{Mg}$ ). The 7075-T6 Al alloy contains zinc as the main dopant (i.e., $5.6 \% \mathrm{Zn}, 1.6 \% \mathrm{Cu}, 2.5 \% \mathrm{Mg}$, and $0.23 \% \mathrm{Cr}$ ). The $3003 \mathrm{Al}$ alloy contains no specific main dopant $(0.0-0.6 \% \mathrm{Si}, 0.0-0.7 \% \mathrm{Fe}, 0.05-0.20 \% \mathrm{Cu}$, and $0.0-0.10 \% \mathrm{Zn})$. The $\mathrm{Al}$ alloys, $2024-\mathrm{T} 3$ and 7075-T6 have high surface protection strength, whereas Al alloy 3003 displays a good pitting corrosion resistance. All three alloys should show aluminum peaks in LIBS spectra, and 7075-T6 Al should display zinc and magnesium peaks and 2024-T Al should display 

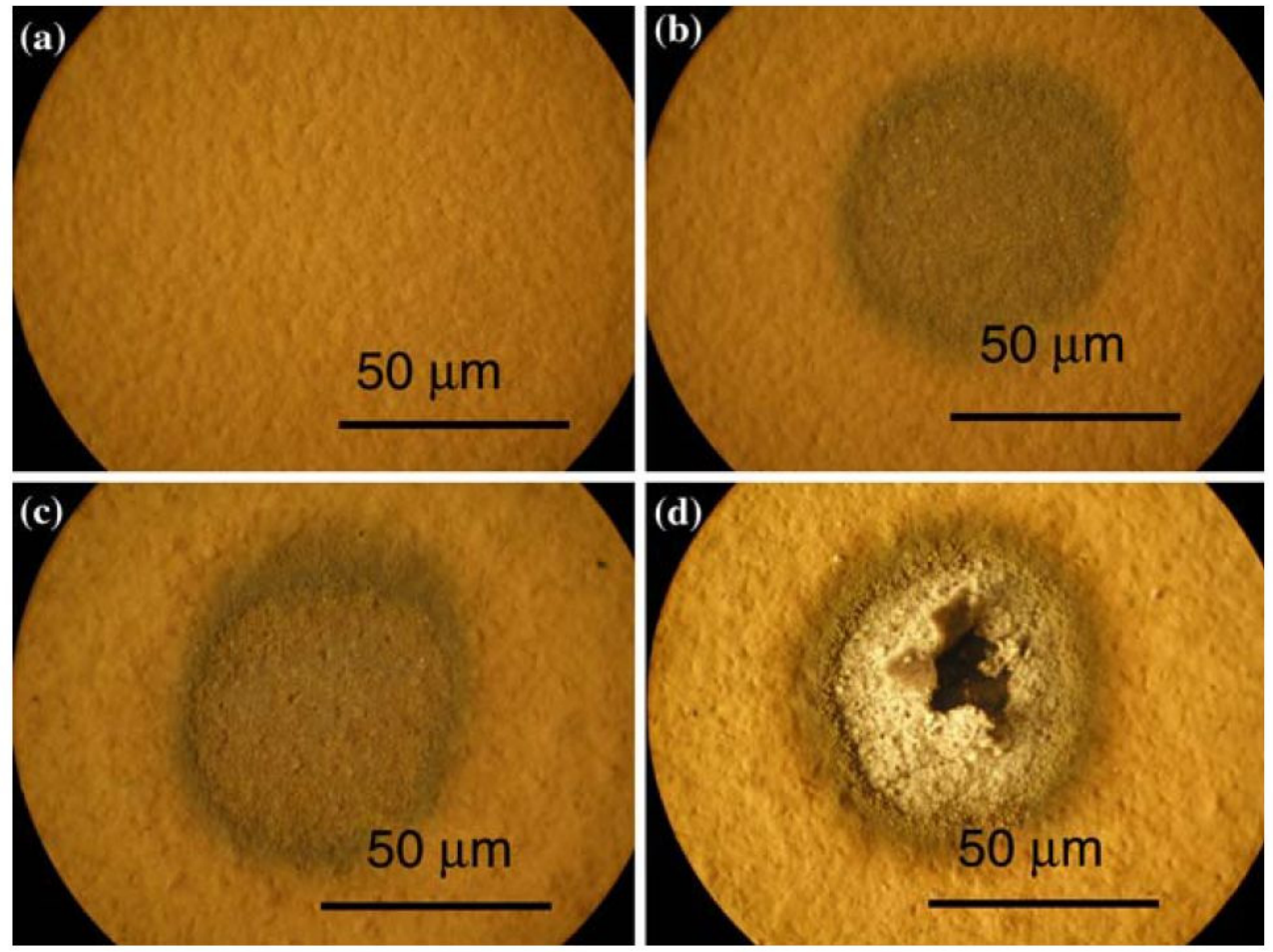

Figure 11. Microscopic images of laser burn patterns on paint film in LIBS experiment after (a) zero, (b) one, (c) two, and (d) five laser pulses

copper and manganese peaks in their breakdown spectra. Figure 12 compares the LIBS spectra recording from $250 \mathrm{~nm}$ to $450 \mathrm{~nm}$ for pure aluminum foil (spectrum a) and three $\mathrm{Al}$ alloys (spectra b, c, and d). As expected, spectrum 13a gives only aluminum peaks at 281.6 $\mathrm{nm}, 306.3 \mathrm{~nm}, 308.2 / 309.3 \mathrm{~nm}, 358.0 \mathrm{~nm}$ and 394.4/396.1 nm.

The spectrum of aluminum alloy shows, in addition to the aluminum peaks, three spectral peaks at $328.2 \mathrm{~nm}, 330.2 \mathrm{~nm}$, and $334.8 \mathrm{~nm}$ are due to zinc (I) ionic states. The 7075-T6 Al alloy gives also the LIBS peaks at $278.6 \mathrm{~nm}, 285.2 \mathrm{~nm}$ and $383.5 \mathrm{~nm}$ for $\mathrm{Mg}$ and at $325.0 \mathrm{~nm}$, $327.7 \mathrm{~nm}$ and $423.0 \mathrm{~nm}$ for $\mathrm{Cu}$ emission. The LIBS technique is not only able to identify the chemical compositions of alloys, but also capable of differentiating the possible contaminants in those alloys. For example, the contamination of $\mathrm{Mn}$ has been detected in $\mathrm{Al}$ 7075-T6 sample as illustrated in spectrum 13d. The contaminants of $\mathrm{Mn}$ and $\mathrm{Mg}$ are observed in spectrum 13b for $\mathrm{Al} 3003$ sample.

The qualitative LIBS spectral assignment is also carried out for pure iron strip, cold-rolled steel, and industrial steel coupons used in the Caterpillar's OEM facility (referred to as CAT machine steel). The bare cold-rolled steel (CRS, SAE 1010) has a composition of $0.08-0.13 \%$ C, $0.3-0.6 \% \mathrm{Mn}, 0.04 \% \mathrm{P}(\max )$, and $0.05 \% \mathrm{~S}(\max )$. The LIBS spectra recorded from $250 \mathrm{~nm}$ to 


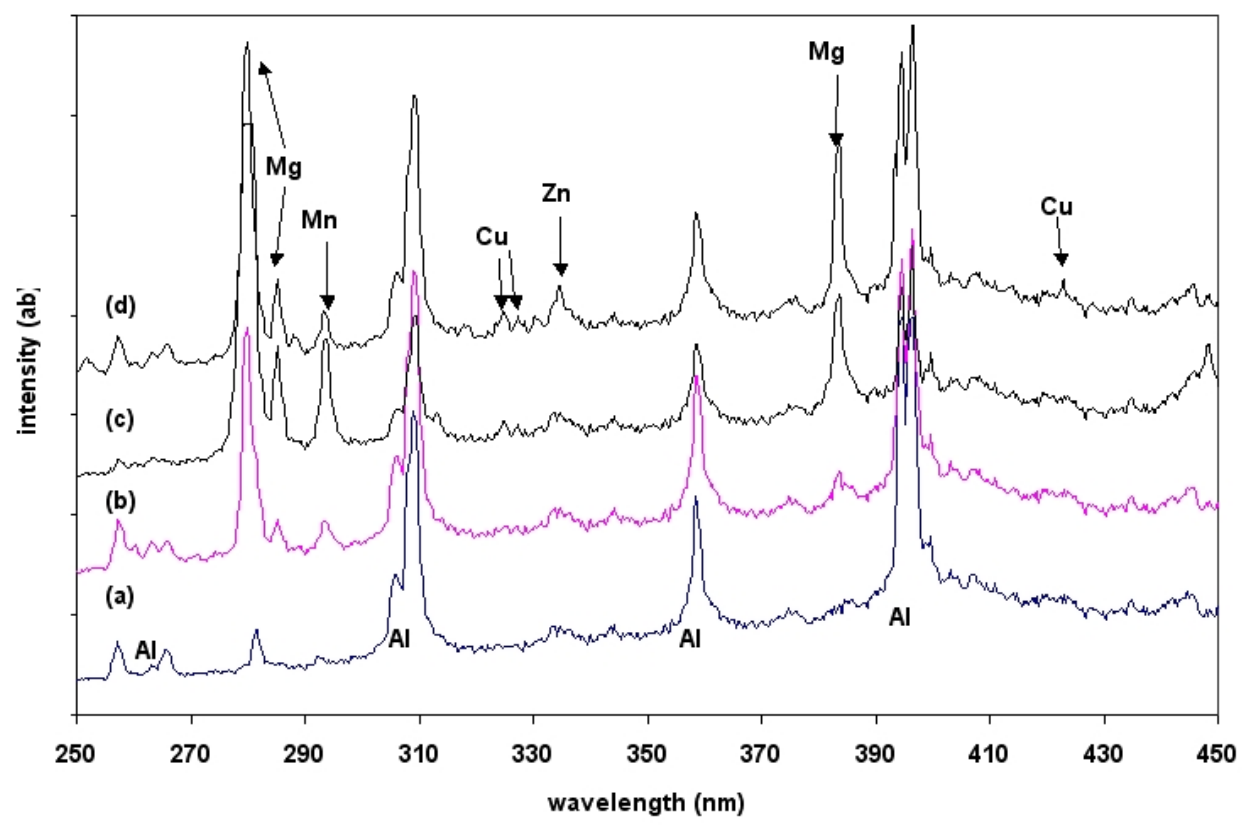

Figure 12. LIBS spectra of aluminum alloys, (a) pure $\mathrm{Al}$ foil, (b) 3003 alloy, (c) 2024-T3 alloy, and (d) 7075-T6 alloy

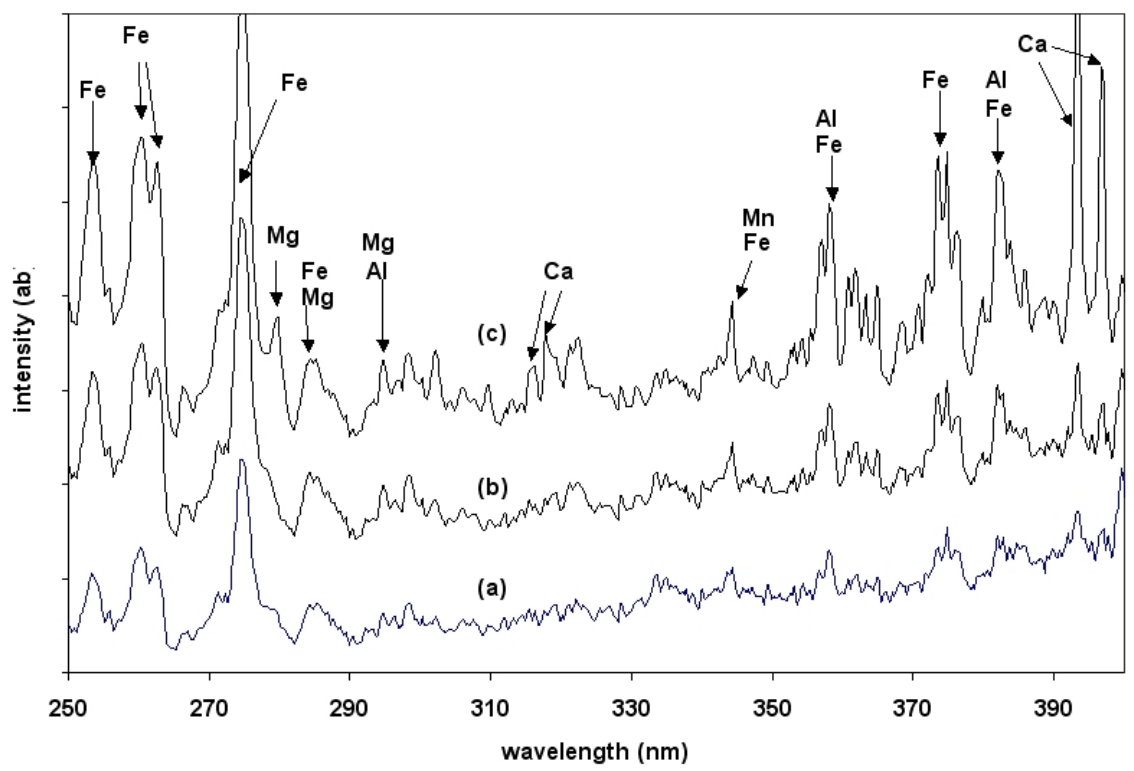

Figure 13. LIBS spectra of steel panels, (a) pure iron piece, (b) cold-rolled steel from Q-PANEL, and (c) CAT machine steel 
$400 \mathrm{~nm}$ are shown in Figure 13: (a) pure iron strip, (b) cold-rolled steel, and (c) CAT machine steel. Spectrum 13a shows LIBS peaks for the pure iron piece at $259.9 \mathrm{~nm}, 262.6 \mathrm{~nm}, 275.0$ $\mathrm{nm}, 358.1 \mathrm{~nm}, 373.4 \mathrm{~nm}$ and $373.7 \mathrm{~nm}$. The laser breakdown emission for CRS as shown in spectrum $13 \mathrm{~b}$ is almost identical to that of the pure iron strip, except an additional peak at $344.3 \mathrm{~nm}$ which may be assigned to $\mathrm{Mn}$ as incorporated in the cold-rolled steel. The spectrum $13 \mathrm{c}$ indicates that CAT machine steel is not a pure iron piece or a standard CRS sample, but rather is a surface pretreated CRS. The surface layer of CAT machine steel contains $\mathrm{Ca}, \mathrm{Mg}, \mathrm{Al}, \mathrm{Mn}$, and $\mathrm{P}$ (at $589.1 \mathrm{~nm}$ ), in addition to $\mathrm{Fe}$. The results indicate that CAT machine steel is an iron phosphate treated CRS, containing a substantial quantity of $\mathrm{Ca}$ and $\mathrm{Mg}$, and some small amount of $\mathrm{Al}$, and $\mathrm{Mn}$ in the phosphating bath.

\subsection{LIBS characterization of surface pretreatment layer on substrates}

Another important part of this research is to establish the effectiveness of LIBS spectral fingerprinting technique for characterizing the composition of any metal surface pretreatment that may have been applied on the substrates. The common metal surface pretreatment used on aluminum alloys today is a chromium-based pretreatment (such as Alodine 1200 or Alodine 1000), which usually contains the chromates (i.e., the compounds contain hexavalent chromium). There are different processes used for surface pretreatment on aluminum alloys; some processes cause a color change of the metal surface to a yellowish color, and some cause no color change at all. In the latter case, it is almost impossible to tell, visually, whether the metal alloy has been pretreated. In this work, the different panels analyzed by LIBS are aluminum alloys of 2024-T3 bare, and 2024-T3 Clad (Clad: a thin layer of pure aluminum on 2024-T3 substrate). The surface pretreatment layer on 2024-T3 bare panel is Alodine 1200. The main active ingredient of Alodine solution is potassium dichromate or strontium chromate. Upon the deposition of a thin layer of pure aluminum on Al 2024-T3 bare, the LIBS spectrum of Al 2024-T3/Clad should give only the pure aluminum peaks which are the same as spectrum 12 a for pure aluminum foil.

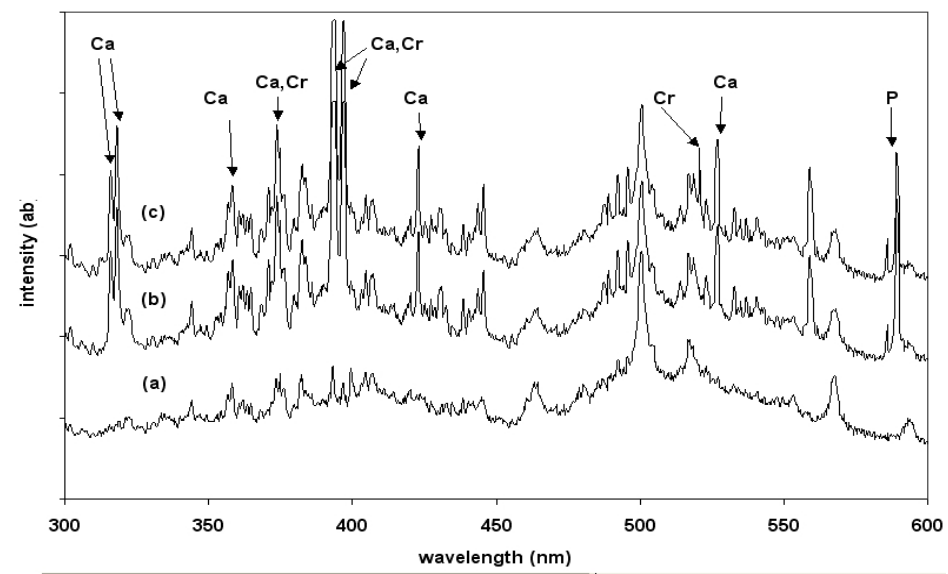

Figure 14. LIBS spectra of surface pretreated layers on CRS substrate, (a) untreated, (b) B-1000, and (c) B-1000/P60 panel 
The surface pretreatment of metal prior to the application of a coating or adhesive is a conventional industrial practice to improve the coating adhesion and inhibit substrate corrosion. For cold-rolled steel, the phosphate conversion coating (e.g., Bonderite ${ }^{\circledR}$ B-1000) and phosphating/chromating (using parcolene 60) pretreatment (e.g., B-1000/P60) are commonly used. The LIBS technique is used to fingerprint the differences in chemical compositions of the surface pretreated layer. The LIBS spectra were taken at the first laser shot spot on (a) untreated CRS panel, (b) B-1000 CRS panel, and (c) B-1000/P60 CRS panel. The laser-induced breakdown spectra of untreated and different chemically treated CRS panels are clearly identifiable and their spectral assignments are marked in Figure 14. The LIBS peaks in spectrum 13a are assigned to Fe and Mn, and are similar to those in spectrum $14 \mathrm{~b}$. The phosphate treated B-1000 panel gives a few additional LIBS peaks in spectrum 14b, such as $P$ at $589.1 \mathrm{~nm}$ and $C a$ at $315.8 \mathrm{~nm}, 318.2 \mathrm{~nm}, 358.3 \mathrm{~nm}, 394.0 \mathrm{~nm}, 423.0 \mathrm{~nm}$, and 527.1 nm. In spectrum 16c, the additional P60 treatment on B-1000 CRS is evident by the appearance of chromium peaks at $373.9 \mathrm{~nm}, 396.8 \mathrm{~nm}$, and $527.1 \mathrm{~nm}$. When these LIBS spectra are compiled in the software system as a standard library file, they can be used to determine if the surface pretreatment processes (including composition, uniformity, and thickness) have been done in according to the products specification.

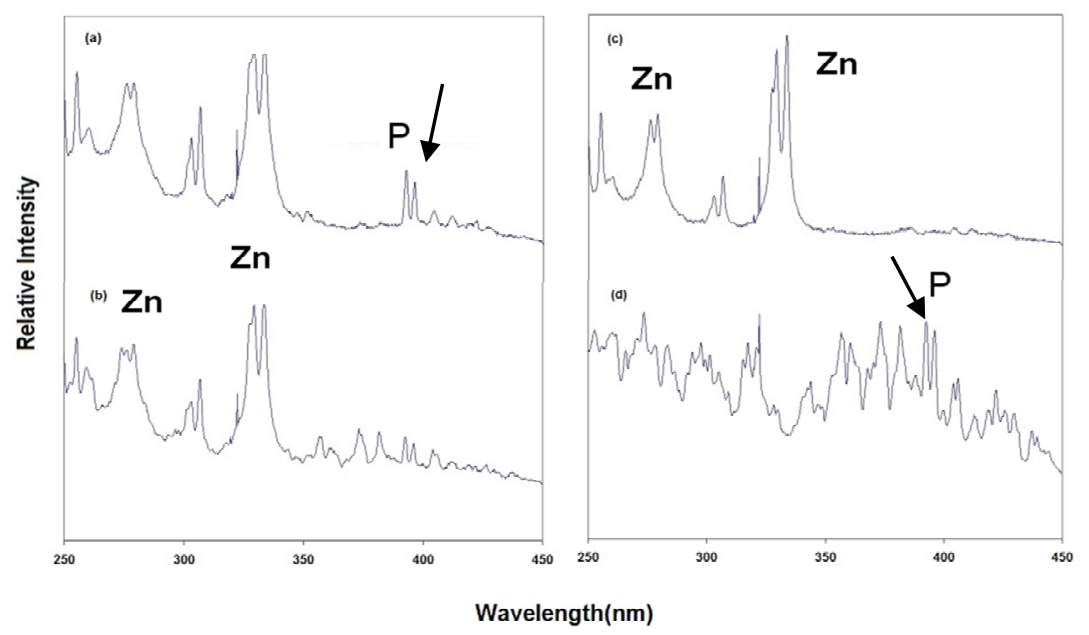

Figure 15. LIBS spectra of EZG panel, (a) from ACT Laboratories, Inc., (b) from China Steel Corp., Taiwan, (c) pure Zn metal piece, and (d) B-1000 CRS panel

Zinc-coated steel (such as Zn/B-1000) is known to inhibit iron corrosion, similar to the effect of zinc anodes. The addition of aluminum to zinc is highly beneficial in improving its corrosion resistance and has resulted in the development of coatings with aluminum contents between 5 and 55\% (i.e., "galvalume" zinc-coated steel). Zinc coatings may be applied to steel panel by hot dipping (i.e., hot dipped galvanized steel, HDG) and electroplating (i.e., electrogalvanized steel, EZG). Due to the high degree of variations in the processing of EZG, HDG, and galvalume, it is critically important to have a versatile materials characterization technique, such as LIBS CoatID, to verify the manufacturing 
conditions of zinc-coated steel at the different factory sites. For a simple illustration, we use LIBS system to test two EZG panels (ACT Laboratories, Inc. vs. China Steel Corp., Taiwan), two HDG panels (ACT vs. Valspar Corp.), and two galvalume panels (Valspar Corp. vs. China Steel Corp.). Figure 15 compares the breakdown emission spectra (recorded from 250 $\mathrm{nm}$ to $450 \mathrm{~nm}$ ) for (a) EZG panel from ACT, (b) EZG panel from China Steel Corp., (c) pure $\mathrm{Zn}$ metal piece, and (d) B-1000 CRS panel from ACT. The LIBS spectra of EZG panels (spectra 15a and 15b) should resemble those of the combined spectra of pure Zn (spectrum 15c) and B-1000 CRS (spectrum 15d), depending on the thickness of both phosphate layer on bare CRS and Zn-galvanized layer on B-1000 CRS panel. By comparing the EZG panels processed at ACT Laboratories, Inc. (spectrum 15a) and that processed at China Steel Corp. (spectrum 15b), it shows that both EZG panels have been subjected to the electrogalvanizing process as stated in their products data sheet. However, the LIBS was able to distinguish a thinner Zn-galvanized layer in the Taiwanese sample, because the steel plate was not covered fully by the Zn-layer and thus the B-1000 steel peaks are still quite visible as shown from $350 \mathrm{~nm}$ to $450 \mathrm{~nm}$ in spectrum 15b. On the other hand, both Zn-galvanized layer and B-1000 phosphate layer in ACT sample are thicker than those in the Taiwanese sample, as indicated by the appearance of a strong $\mathrm{P}$ emission doublet and also several intense $\mathrm{Zn}$ peaks. In ACT sample, the thicker $\mathrm{Zn}$ and phosphate layers give a higher coverage on the steel panel, and thus almost no steel peak is observed in Figure. 15a.

\subsection{LIBS identification of paints and coating ingredients}

Eleven paints from Caterpillar's OEM coating facility were selected for the identification test by LIBS technique, and listed in Table 1.It is noted that all paint samples have the same color (i.e., Caterpillar yellow) with only slightly different tint, the differences are hardly distinguishable with naked eyes. Samples 1 to 4 are two-pack urethane paints, 5 to 7 are two-pack epoxy paints, and 8 to 11 are one-pack alkyd paints. The paint samples 1 and 5-9 are primers, whereas those of 2-4 and 10-11 are topcoats. The processing methods used in coating applications, such as drying and thermal curing conditions are specified in the remark column of Table 1. The paint systems used in Caterpillar's OEM facility were specifically formulated by the paint manufacturers that have been successfully tested and verified for the required protection of heavy duty machines. Once the paint formulations were established, the manufacturer would strictly maintain the composition of paint ingredients in an effort to achieve a good quality control. This is the reason that LIBS technique may be effectively used for fingerprinting a specific brand of paint.

Figure. 16 displays the LIBS spectra for the eleven paint samples listed in Table 1. The topcoat paints (samples 2-4 and 10-11) display a relatively simpler LIBS spectrum than that of the primer paints (samples 1 and 5-9). In all spectra, the LIBS peaks grouped around $250 \mathrm{~nm}$ may be attributed to iron oxide as a dispersed pigment. The peaks originated from calcium at $393.3 \mathrm{~nm}$ and $396.8 \mathrm{~nm}$ are predominantly shown in the primer type paints. Calcium carbonate has been used at high levels for certain paints because of their low oil absorption. Calcium compound imparts some film structure to the wet paint by improving the stability to sedimentation of other heavier pigments in paint. It is not 
surprising that primer paint for CRS coating contains a rich calcium ingredient. The primer paints, samples 1, 6, 8, and 9, are shown to contain not only calcium carbonate but also magnesium silicate, as their corresponding LIBS peaks displayed at $279.8 \mathrm{~nm}$ and $383.5 \mathrm{~nm}$.

In the previous section, the peak picking algorithm has been successfully used for characterizing substrates and surface pretreatment layers which contain only a few elements and have the well-characterized LIBS peaks. Since paint formulation contains a rather complex mixture of multi-ingredients, thus the decisions for paint identification could best be made by peak correlation algorithm. Any spectral pairs of identical samples must show a $100 \%$ correlation value. Due to the possible fluctuation in laser power density, the inhomogeneity of paint film compositions, and the variation in thickness of a paint film, the LIBS spectra for both testing and reference samples were measured at ten (10) different spots for each painted panel. A statistical average spectrum was made to achieve the reproducibility for the identification of a paint sample. The correlation values of identical samples show a 96-99\% of reproducibility. On the other hand, the correlation values between two different types of paints, such as urethane and epoxy, show to be around $86.8 \pm$ $0.7 \%$. These correlation values give a clear discrimination between types of paints. Based on the correlation values, we can say that the test sample has a good match to the reference sample, if the correlation values are greater than $95 \%$. We estimate from the use of peaks correlation algorithm, the LIBS system is capable of correlating the test paint samples to the standard paint films to give a $90-95 \%$ of perfect match. The remaining $5-10 \%$ near match or no match may due to the complex nature of paints and coatings, including the possible surface contaminations. In this case, a careful spectroscopic analysis is further required to achieve the proper paint sample identifications.

\begin{tabular}{|l|l|l|l|}
\hline Sample No. & Resin & Type of paint & Remark \\
\hline 1 & Urethane & Primer & 2-part system, cured at $66^{\circ} \mathrm{C}$ \\
\hline 2 & Urethane & Top coat & 2-part system, low temperature curing \\
\hline 3 & Urethane & Top coat & 2-part system, high temperature curing \\
\hline 4 & Urethane & Top coat & 2-part system, cured at $66^{\circ} \mathrm{C}$ \\
\hline 5 & Epoxy & Primer & Low temperature curing $\left(54^{\circ} \mathrm{C}\right)$ \\
\hline 6 & Epoxy & Primer & Medium temperature curing $\left(66^{\circ} \mathrm{C}\right)$ \\
\hline 7 & Epoxy & Primer & High temperature curing $\left(82^{\circ} \mathrm{C}\right)$ \\
\hline 8 & Alkyd & Primer & Air-dry system \\
\hline 9 & Alkyd & Primer & Baking system \\
\hline 10 & Alkyd & Top coat & Air-dry system \\
\hline 11 & Alkyd & Top coat & Baking system \\
\hline
\end{tabular}

Table 1. The sample paints obtained from Caterpillar Inc. 

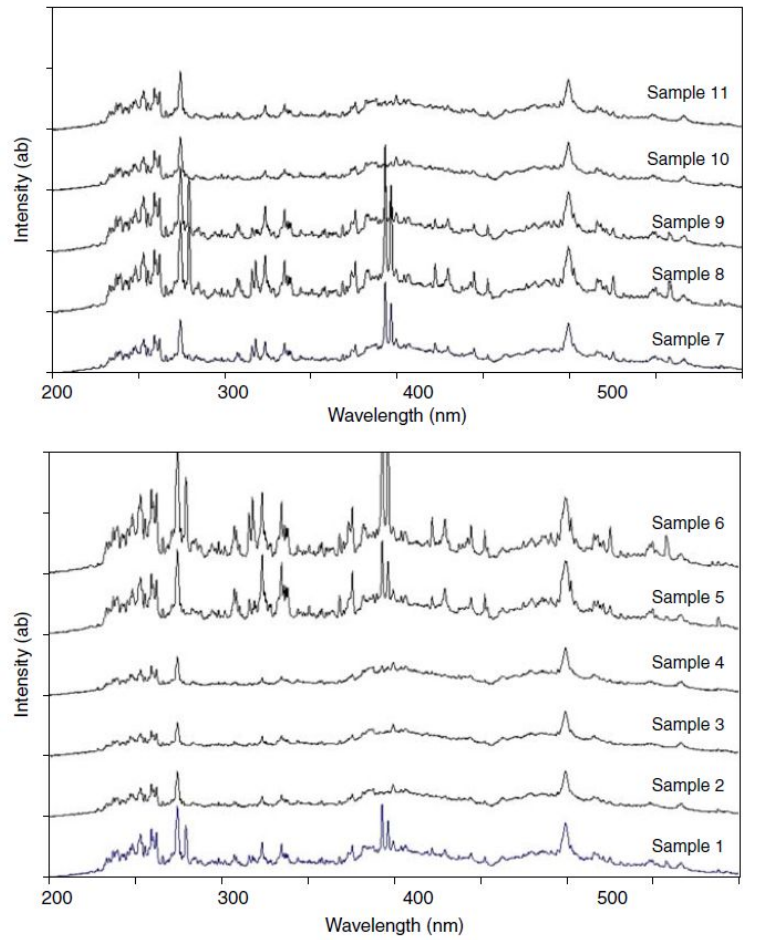

Figure 16. LIBS spectra for the eleven industrial paint samples obtained from Caterpillar Inc.

b. Organic and bio material screening

Biomaterial application has two areas depending on the analytical goal. The first goal is the analysis of metallic component in the biomaterial. The conventional elements like $\mathrm{Na}, \mathrm{K}, \mathrm{Ca}$, $\mathrm{Mg}$ are included in plant, wood, grain, tissue and bio-remains. Their analysis is similar to other solid samples except those samples include high level of carbon compound. The second application of biomaterial is characterization of biomaterial itself. Breakdown spectrum from LIBS can have information of specific sample group. One of the researches has been made for classification of bacterial strains by major components analysis with LIBS[35]. A pulsed Nd:YAG laser (Continum, Powerlite8000, 10-ns pulse width) was focused on the sample solution by using a $20-\mathrm{cm}$-focal-length lens. The frequency-doubled laser output at $532 \mathrm{~nm}$ was used for plasma generation. The laser power used on the bacteria analysis was $50 \mathrm{~mJ} /$ pulse. A light collecting optical fiber was placed near the sample surface to detect the plasma emission which was sent to a spectrometer (Acton research, 1200 grooves/mm grating). The spectra were captured with a photodiode-array detector (OMA IV, EG\&G, 1024 array) with a spectral resolution of $0.061 \mathrm{~nm}$. The available spectral range is limited to about $50 \mathrm{~nm}$ from the full OMA coverage of $76 \mathrm{~nm}$ because of the shadow of optical components in the monochromator. The OMA output was processed and stored by using a personal computer. 
Several bacterial strains have been classified depending on their major components analyzed by laser-induced breakdown spectroscopy (LIBS). The bacteria studied were Bacillus megaterium, B. Subtillis, B. Thuringiensis, and Escherichia Coli. Each strain was streaked on the cultivating plate and grown to prepare the colonies of vegetative or spore forms. The major inorganic components of the bacteria samples, including $\mathrm{Ca}, \mathrm{Mn}, \mathrm{K}, \mathrm{Na}$, carbon, and phosphorus, were clearly identified from the LIBS data. The vegetative forms of bacteria, beginning step of bacteria life, represent the similar quantities of analytical components between bacteria. After the bacteria have used up the available food supply the bacillus enter into their non-vegetative spore form. The bacteria spores accumulate a lot of calcium on the spore shell which showed strong emission of $393.7 \mathrm{~nm}$ and $396.9 \mathrm{~nm}$ in the LIBS spectrum. The diverse emission from phosphate at $588.1 \mathrm{~nm}$ and $588.7 \mathrm{~nm}$ provides a fingerprint of the bacteria. The relative change of inclusions of bacteria was clearly distinguished on the 2-dimensional chart of the bacterial components. This work demonstrates the potential of this method for the rapid and precise classification of bacteria with minimum sample preparation. The quick process of LIBS expected to be used in the real-time analysis of intentionally cultured bulk bacteria in the industrial or weaponized microorganism.

\subsection{Preparation of microorganism}

Five types of bacterial samples were prepared from the biology lab. Te laboratory stock stains used were Bacillus Megaterium QM B1551 (seven indigenous plasmid), Bacillus Megaterium PV361 (QM B1551 with all plasmid removed), Bacillus Subtillis 168M, Bacillus Thuringiensis T34, and Escherichia Coli carrying pHT315. QM and PV of B. Meg are closely related on their genetic origin and B. thu. is a divergence of B.sub. Only E. Coli is a gramnegative genus among them with antibiotic and enzyme resistive cell wall, and E. Coli does not make dormant spore on the contrary to other bacillus. All bacterial genera used are biosafety level 1 (non pathogenic). Each stain was streaked on Luria-Bertani (LB) plates (10.0 g tryptone, 5.0 g yeast extract and $5.0 \mathrm{~g}$ of $\mathrm{NaCl}, 15 \%$ agar, in $1 \mathrm{~L}$ double distilled $\mathrm{H}_{2} \mathrm{O}$ ) and grown overnight for both tests. LB plates were then spread with $0.1 \mathrm{~mL}$ of culture and grown for 24 hours for confluent plate test. The same set of vegetative bacteria were kept more than 5 days at room temperature to be spore forms after consuming nutrient and drying.

The series of bacteria cultured on the plastic dish are measured on the LIBS system without any pretreatment. The bacteria colonies on the top of the culturing medium (LB) are grown to roughly a $0.5 \mathrm{~mm}$ thickness in the wet condition. The areas of the colonies are wide enough for manual mounting on the sample stage and focusing into less than 50 micron diameter of breakdown diameter. The LIBS spectra from bacteria and culturing medium in the UV and visible spectral range have higher background level compare to solid metallic samples such as aluminum, copper and steel. The lack of light absorption on the sample requires a more intense laser for the breakdown. The threshold intensity of the laser pulse for stable and sufficient breakdown was $40 \mathrm{~mJ}$. This value is bigger than $10-20 \mathrm{~mJ}$ of the solid LIBS application because the solid samples are not transparent and thus absorb more of the light. 


\subsection{LIBS spectra of bacterial strains}

Although the entire spectrum, from the UV to visible range was initially scanned it was experimentally determined that the three ranges mentioned contained most of the peaks of possible interest. The presence of certain elements was investigated in the micro-organisms such as chlorine, sulfur, phosphorous, calcium, sodium, and potassium. Also of interest were the possible trace elements such as zinc, magnesium, manganese, cadmium, nickel, cobalt, and strontium. Listed in the table are peaks that could be candidates for these possible elements. Because of the atomic elemental nature of the LIBS we expect to match the major or minor peaks to the above mentioned elements certain series of peaks. The peaks were matched to the possible elements in microorganism using the library available in the NIST data base In our preliminary studies we were unable to match several trace elements such as $\mathrm{Mg}, \mathrm{Cd}, \mathrm{Ni}, \mathrm{Co}$, and $\mathrm{Sr}$. The complexity of the iron emission can make it difficult to distinguish it from other elemental peaks of interest. Despite the different outward appearance and life cycle of the bacterial species they all shared a similar elemental composition. Strong peaks were found at $252.8 \mathrm{~nm}, 279.7 \mathrm{~nm}, 393.7 \mathrm{~nm}, 396.9 \mathrm{~nm}, 398.3 \mathrm{~nm}$, $578.9 \mathrm{~nm}, 588.1 \mathrm{~nm}$, and $588.7 \mathrm{~nm}$. Using a spectrometer with $1200 \mathrm{gr} / \mathrm{mm}$ grating at $50 \mathrm{~nm}$ blocks of the spectrum four of the major peaks of interest were identified. The spectra shown in Figure 17 are emissions from bacteria around $400 \mathrm{~nm}$. The peaks at $393.7 \mathrm{~nm}$ and $396.9 \mathrm{~nm}$ attributed to the calcium atomic transition $4 s^{2} S_{0,1 / 2}-4 p^{2} P_{1,1 / 2}$, and $4 s^{2} S_{0,1 / 2}-4 p^{2} P_{0,1 / 2,}$ the strongest emissions from calcium used in many other atomic spectroscopy. These calcium emission were verified by using $\mathrm{CaCl}_{2}, \mathrm{CaPO}_{4}$ as spectral references.

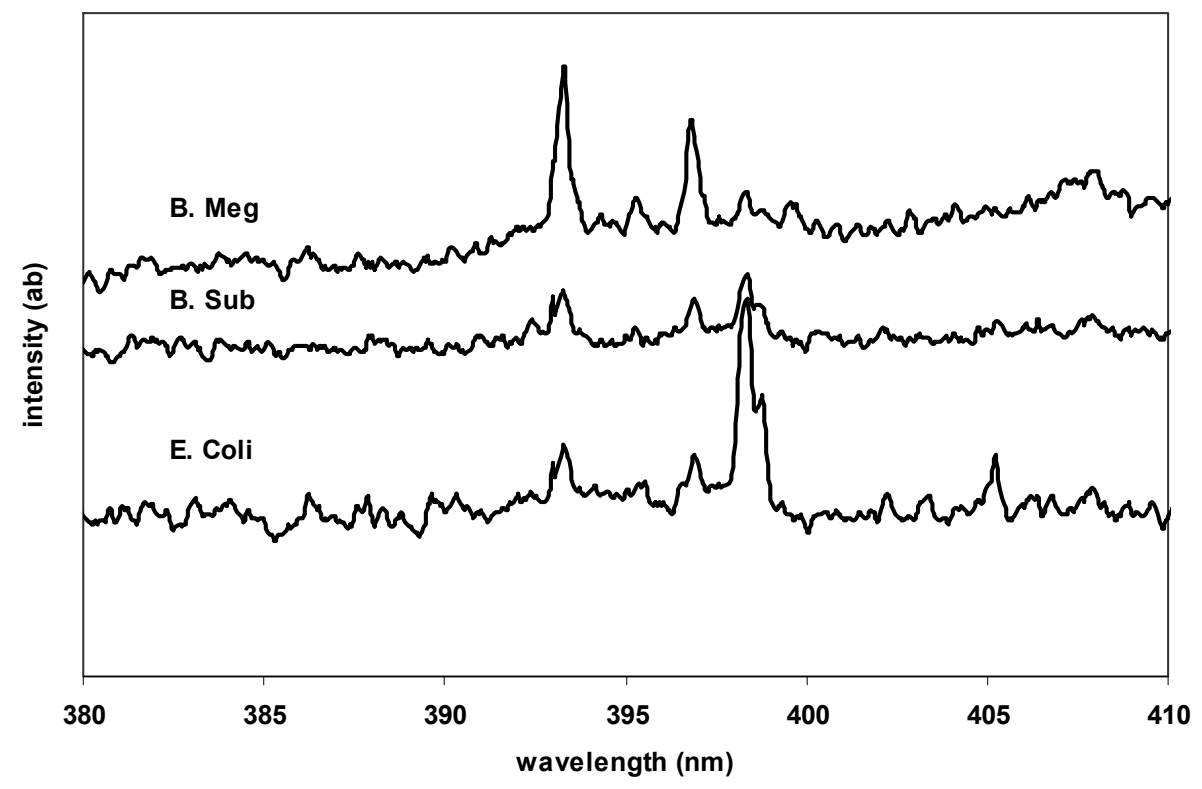

Figure 17. Spectrum after cell death and sporulation of the bacillus has occurred. 
At the spore stage of the bacteria, after remaining for 5 days at room temperature to consume all of the nutrients, most of the surface water evaporated. It is known that the water content of spores is only about $10-30 \%$ of the water content of vegetative cells (active bacteria) to survive spores at levels of dehydration that would kill vegetative cells. The low water content also provides the spore with chemical resistance (to chemicals such as hydrogen peroxide) and it causes the remaining enzymes of the spore cell to become inactive. This inactivity makes the immunological detection hard to improve sufficient sensitivity. One chemical produced by spores that is thought to lend to their high resistance is dipicolinic acid. Dipicolinic acid interacts with calcium ions to form calcium dipicolinate, which is the main substance believed to lend spores their resistance and represents about $10 \%$ of the dry weight of a spore. The intensity of calcium is strong on the spore sample of $B$. Meg, B. Sub., and B. Thu. colonies. E. Coli colonies have low calcium content and the composition does not change after aging. This is a proper result that because $E$. coli does not make spores. The spore cell also contains special spore proteins. These protective wall structures are highly resistant to heat desiccation, chemical disinfection and radiation. These functions are to protect DNA from harsh environments, but also disturb measurement chemical property on the conventional spectroscopy. Another component of spores that contributes to their resistance to chemical agents is the strong spore coat, which is composed of highly cross-linked keratin. Laser breakdown is strong enough to break the protective shell of the spores and take out inner component of the cell. The peak at $398.3 \mathrm{~nm}$ is overlapped to Mn emission from library data. The strong intensity in this wavelength could not be assigned as $\mathrm{Mn}$ because of relative intensity of $\mathrm{Mn}$ in other wavelengths. On the other hand, the peak on this wavelength is observed on the samples of organic compounds such as LB of culture medium, cellulose, and many organic polymers. This result leads to assigning this peak as carbon compound fragment.

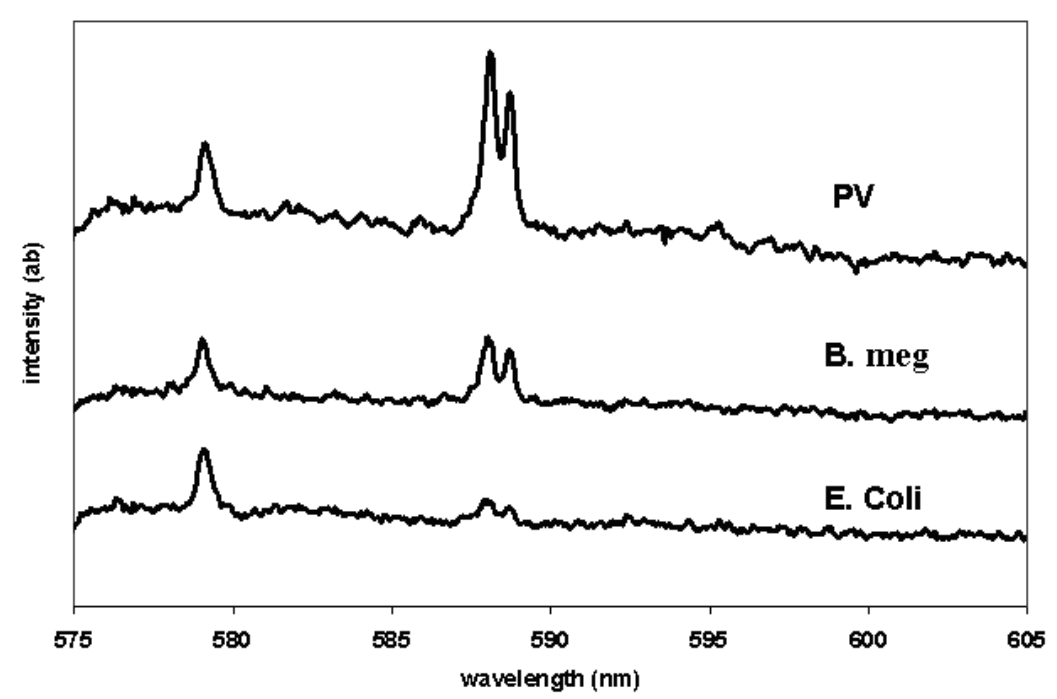

Figure 18. Spectrum to show the amount of phosphate compound in three different bacteria samples. 
Figure 18 shows LIBS spectra of 3 bacteria colonies. The doublet peaks appeared at $588 \mathrm{~nm}$ is due to phosphate functional compound in the bacteria. In spite of phosphorus elemental emission library doesn't have significant emission on this wavelength, we assign this peak as phosphate because of strong peak observed from some other phosphate compound examination. $P V$ shows strongest peak at the phosphate emission. E. coli shows weaker intensity. The other bacteria have intermediate peak height, like B. meg. in the middle. The amount of phosphate seems to be related to the strain of the bacteria not to the life progress of the microorganism. The phosphate intensities are always weak at the vegetative step and then increase at the spore. The increment of phosphate is biggest for $P V$ bacteria. The peak at $578.9 \mathrm{~nm}$ is not assigned properly for a certain component of our culturing system. Every bacterial sample and culturing medium shows similar intense peak at this wavelength. With the result of LIBS experiments for several organic compounds, this component is identified as an organic functional group. The proper identification is still on the research.

Figure 19 shows distribution of bacteria on the spread chart of intensity ratio. The $\mathrm{X}$ axis is the intensity ratio to represent calcium amount on the bacteria samples. B. meg and its plasmid treated $P V$ bacteria strains are at high amount of calcium. B. sub and B. thur are at a relatively lower than B. meg strains. E. coli does not store calcium whether vegetate or aged colonies. The outstanding feature of phosphate intensity is on the difference of $B$. Meg and $P V$. These two strains are genetically same organism but only $P V$ have been removed their plasmid from $B$. $M e g$ type bacteria. The modification of $P V$ leads more storage of phosphate in the spore cells.

To identify the selective intake of certain element from culturing medium, we examine the components of the culture medium. The calcium in the medium was lower level than LIBS detectable. This result shows the sporation of bacteria absolutely needs calcium and they collect calcium very efficiently.

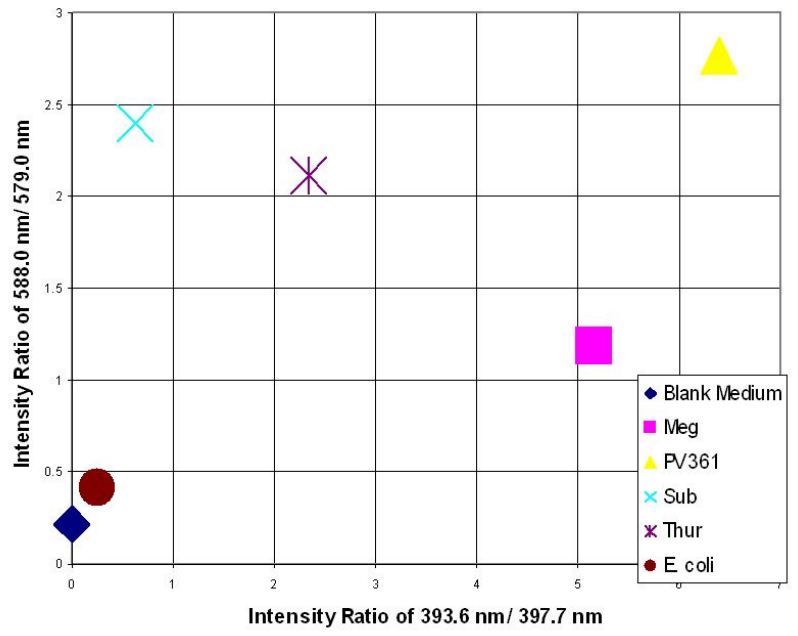

Figure 19. Intensity ratio of two selected wavelength range plotted against each other. The values for $X$ axis are made the intensity of the samples at $393.6 \mathrm{~nm}$ divide by their intensity at $398.24 \mathrm{~nm}$. The values for $\mathrm{Y}$ axis are made by intensity of the samples at 58 
c. Application of LIBS for metallic component in aqueous solution

As mentioned at the LIBS property, solid samples are most convenient and strong LIBS signal. Liquidor gas samples need more specific optical arrangement to generate breakdown and emitting light collection. There are several ideas to overcome the sampling difficulty of gas and liquid samples. One of the publications here is a typical sample type conversion from liquid sample to solid with concentrating effect. Ion-exchange resins are conventional substances used to capture metal ions and hold them in the solid resin matrix. Chemically activated microporous membranes functionalized with polycarboxylic acid are typically employed[36]. The matrix encapsulation technique has been applied to collect trace metals from water, and converting metal ions to a solid form. The pre-concentration of analyte from a liquid sample into the ion exchange membrane was extensively studied for LIBS measurement by Schmidt and Goode[37]. The captured $\mathrm{Cu}$ on the small area of the ion exchange membrane has shown that the pre-concentration can provide a large volume of liquid filtration. Many of the test elements gave results in the sub $\mathrm{mg} / \mathrm{L}$ range of detection limits by liquid filtration method. Total chromium elements were captured in the membrane and measured by LIBS[38] in the range of $\mathrm{ng} / \mathrm{mL}$ detection limit, where $\mathrm{Cr}(\mathrm{VI})$ was chemically converted to $\mathrm{Cr}(\mathrm{III})$. A fast analysis technique with automated LIBS analyzer is configured for monitoring of metal ions in water[39]. The ion exchange membrane is used to develop Copper solutions were used to establish pre-concentration parameters. The chelating resin based filter membrane was used to capture $\mathrm{Cu}$ ions in water. A series of standard solutions were filtered through the ion exchange membrane by using a vacuum suction system to reduce the filtration time. The LIBS signals of copper absorbed on the layers of the membrane were investigated to determine parameters for practical analysis.
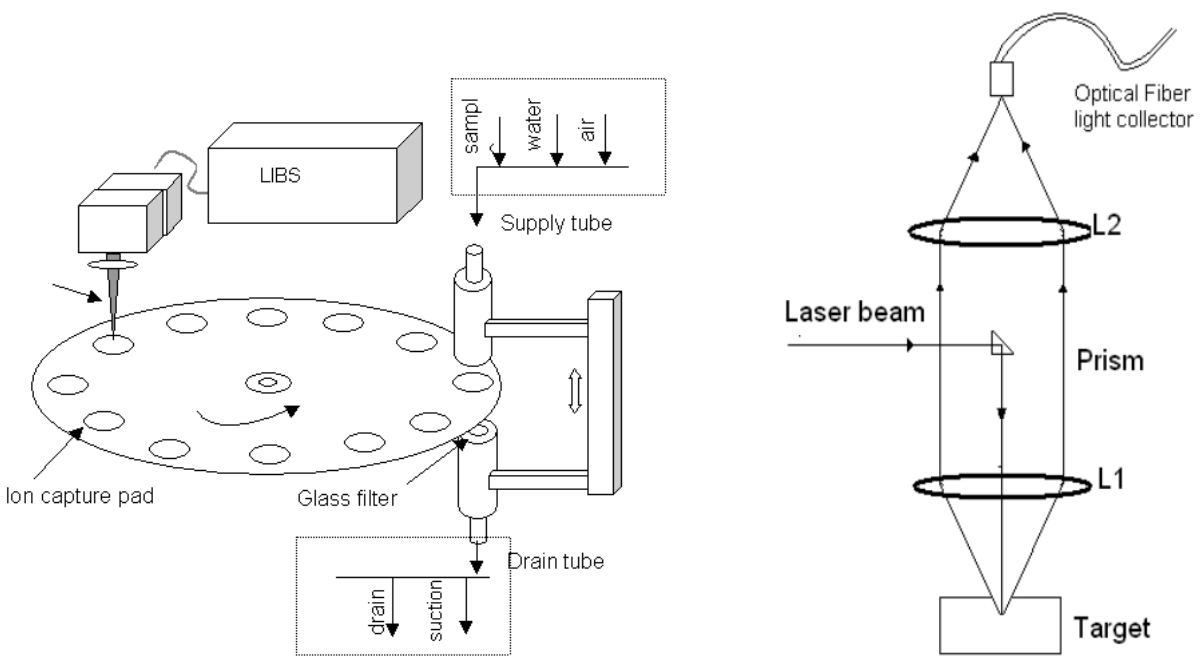

Figure 20. Experimental set up for ion-capture filtering and LIBS (top) and detail of collection optics (bottom). 


\subsection{Solution samples and instrumentation}

The stock solutions were prepared using copper salts as the source of the copper ions from, cupric nitrate $\left(\mathrm{Cu}\left(\mathrm{NO}_{3}\right)_{2} \cdot 3 \mathrm{H}_{2} \mathrm{O}\right.$, Fisher), cupric chloride and cupric sulfate, at a $500 \mathrm{mg} / \mathrm{L}$ concentration, which were then diluted to make a series of test solutions with well-defined concentrations. A copper sheet $(99.9 \% \mathrm{Cu})$ was obtained. A commercially available extraction membrane was obtained from 3M filtration Products (St. Paul, MN). The original purpose of using the ion-exchange membrane was to extract multivalent metal ions for environmental analysis by chelating in the PTFE matrix. The ionic selectivity of the membrane is known to follow roughly along the EDTA complex formation constants. The membrane was affixed between the edges of two Teflon tubes with a $12 \mathrm{~mm}$ inner diameter. The upper tube was connected to the supply manifold valve for switching sample solutions, flushing water and drying air. The lower tube was depressurized for filtering and suction through a drain reservoir. The drainage tube held a round glass filter to support the membrane during solution filtering.

For this LIBS system, an ion-exchange membrane concentrator was assembled as shown in the Figure 20 for use in the experiment. A fiber optic cable collected the breakdown emissions through collection optics (L1 and L2) and directed them to a fixed-grating spectrometer. The spectrometer has a 3600 -sensor array and covers a spectral range of 250 $\mathrm{nm}-800 \mathrm{~nm}$. The samples on the motorized stage were moved $0.5 \mathrm{~mm}$ to $1 \mathrm{~mm}$ stepwise to collect an averaged spectrum from a membrane sampler.

\subsection{Operation conditions for membrane concentrator}

A $10 \mathrm{mg} / \mathrm{L}$ copper solution prepared from $\mathrm{Cu}\left(\mathrm{NO}_{3}\right)_{2}$ was used to test the filtering conditions of the membrane concentrator. The LIBS spectra were obtained in the measurable intensity range. The inset in Figure 21 shows the major copper peak that was used for this test. The metal capturing function of the ion exchange membrane is known as that of the EDTA chelating process, therefore the chelating speed must be fast enough to capture all the copper ions during filtration. The estimated filtering time through a $0.2 \mathrm{~mm}$ thickness of membrane filter is $3 \mathrm{~min}$ when $20 \mathrm{~mL}$ of solution is passed through a $12 \mathrm{~mm}$ diameter filter at the vacuum suction pressure of $20 \mathrm{kPa}$. The amount of copper captured on the membrane filter should be proportional to the observed LIBS intensity. As shown in Figure 21, the average intensity for the LIBS peak at $324.75 \mathrm{~nm}$ is almost constant throughout the changes of suction pressure which control the filtering speed of test solution. The experimental results show that there is a large uncertainty in capturing $\mathrm{Cu}$ on membrane filter (a large error bar in Figure 21) when the sample solutions are filtered very slowly with low suction pressure. If the filtration process took more than 30 minutes at a pressure of less than $10 \mathrm{kPa}$, the error in measurement increased. It was also found that soaking for extended periods of time in test solution would lead to wrinkles on the membrane filter, due to membrane swelling. On a wrinkled membrane, the liquid filtration path is biased in certain areas of the filter paper resulting in uneven dispersion of captured ions on the membrane surface. On the other hand, when the test solution was filtered at a very high speed, i.e., the suction 
pressure is more than $80 \mathrm{kPa}$, the ions just pass through the membrane. A $20 \mathrm{~mL}$ solution takes only $10 \mathrm{sec}$ to filter and ions begin to pass through without being captured which leads to a weaker intensity on the LIBS spectra. Based on this membrane operation test, a suction pressure of $30 \mathrm{kPa}$ was maintained as the standard condition, so $20 \mathrm{~mL}$ of solution can be completely filtered within 2 minutes.

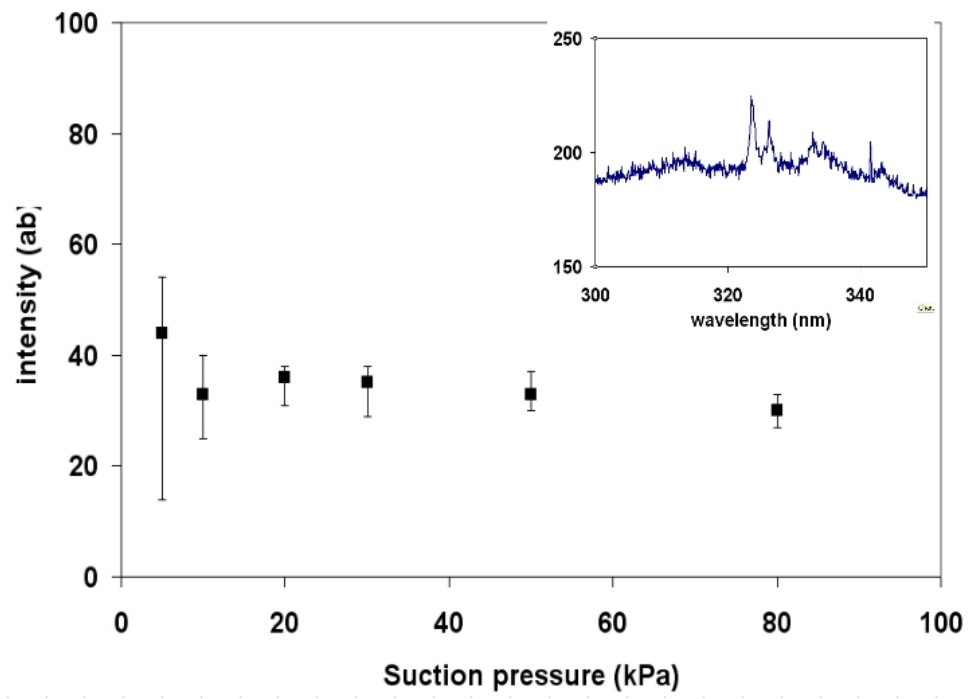

Figure 21. LIBS intensity of $\mathrm{Cu}$ at $324.7 \mathrm{~nm}$ sampled by filtering at different suction pressure. The inset shows the $\mathrm{Cu}$ emission that was concentrated from a $10 \mathrm{mg} / \mathrm{L}$ of $\mathrm{Cu}$ solution.

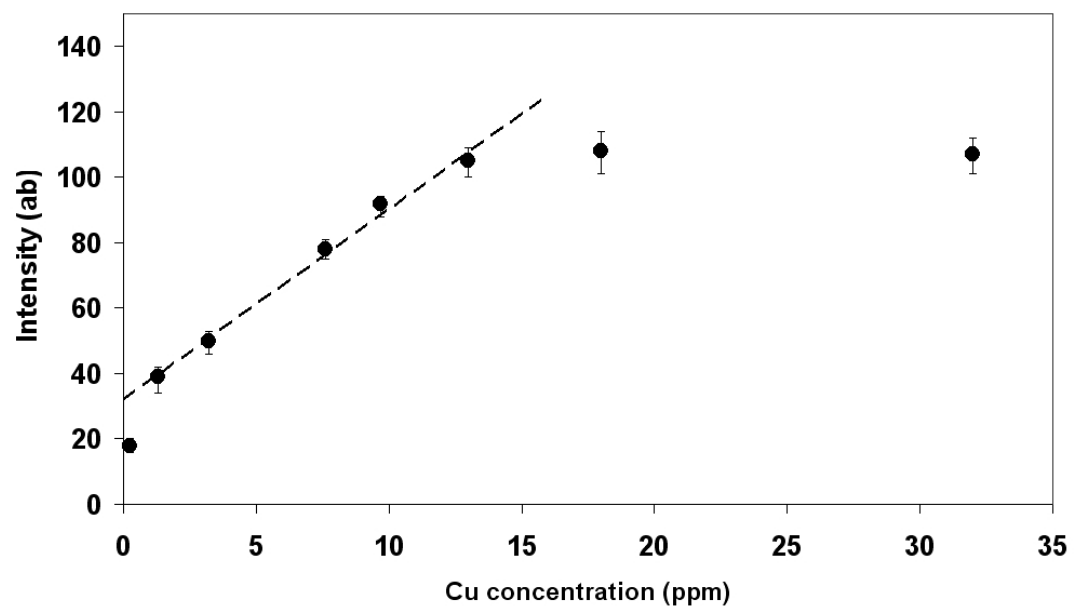

Figure 22. LIBS intensity measurements for low concentration samples. Each of the data points were obtained by averaging five individual measurements on a single filter surface at five different spots. The line was made using the data points from $0.5 \mathrm{mg} / \mathrm{L}$ to $15 \mathrm{mg}$ 


\subsection{LIBS intensity from the top membrane surface}

Figure 22 shows LIBS intensity of low concentration samples (a few $\mathrm{mg} / \mathrm{L} \mathrm{Cu}$ solutions) for the peaks at $324.75 \mathrm{~nm}$. All data points were obtained by averaging five individual measurements at five different spots on a single membrane filter. Since the sample surface required for a single laser breakdown shot is less than $0.1 \mathrm{~mm}$ in diameter, multiple measurements and their average values are easily obtained over the surface of the membrane filter. The LIBS intensity of copper displays a linear correlation over concentration ranges below $15 \mathrm{mg} / \mathrm{L}$. The line in Figure 22 was made by using the data points from $0.5 \mathrm{mg} / \mathrm{L}$ to $15 \mathrm{mg} / \mathrm{L}$ of $\mathrm{Cu}$ solutions with the exclusion of higher concentration data. The results give a relatively too narrow dynamic range for general analytical use. However, the correlation of the line is $\mathrm{R}^{2}=0.9926$ and it can be an acceptable analytical calibration concentration. The reason for the extremely limited dynamic range is investigated further in the next section.
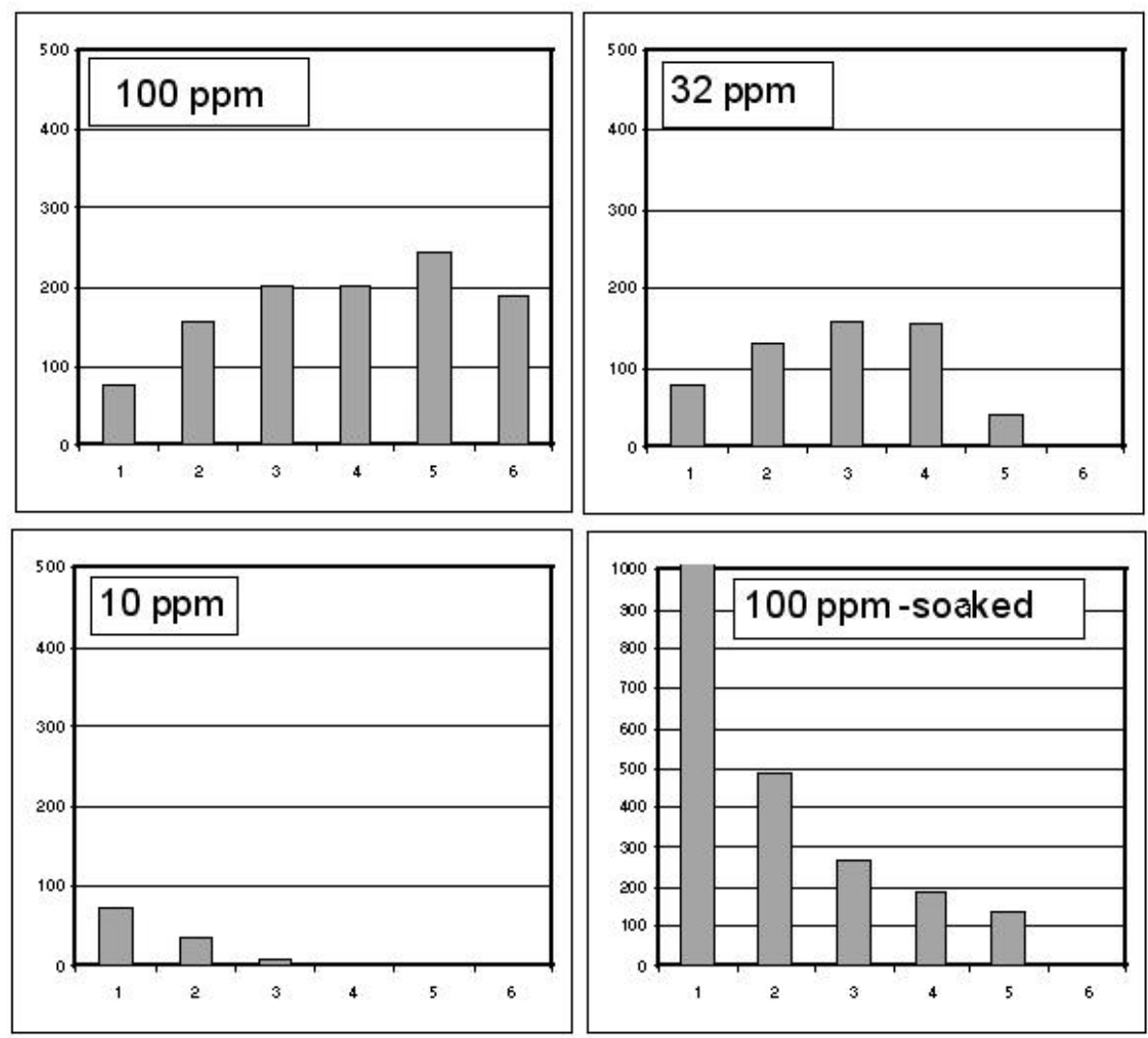

Figure 23. Intensity change by consecutive laser shots. The $\mathrm{Cu}$ concentration in the sample solutions for the membrane filtration is $100 \mathrm{mg} / \mathrm{L}, 32 \mathrm{mg} / \mathrm{L}$ and $10 \mathrm{mg} / \mathrm{L}$. The membrane filter soaked for 24 hours in $100 \mathrm{mg} / \mathrm{L}$ solution (lower right) shows intensity greater 


\subsection{Depth effects on ion-capture membrane}

In Figure 22, when the concentration of $\mathrm{Cu}$ solution is higher than $20 \mathrm{mg} / \mathrm{L}$, the LIBS intensity of $\mathrm{Cu}$ at $324.75 \mathrm{~nm}$ seems to lose its proportionality relationship to the concentration and remain constantly extended to $35 \mathrm{mg} / \mathrm{L}$. Initially, the retention capability of the membrane was suspected but this was shown not to be the case because the filtrate (drain) from high concentrations did not contain copper ions. To verify the effects of depth profiling on ion-capture membrane, further investigation was done using multiple laser shots at the same spot of membrane. Figure 23 shows the LIBS intensity change by consecutive laser shots at a single membrane point. The intensity of the first laser shots from the filtered samples of $100 \mathrm{mg} / \mathrm{L}, 32 \mathrm{mg} / \mathrm{L}$ and $10 \mathrm{mg} / \mathrm{L}$ solutions are unexpectedly similar, and then the next laser shots show intensity change relative to the solution concentration. The $100 \mathrm{mg} / \mathrm{L}$ sample makes strong LIBS intensities until the $10^{\text {th }}$ laser shot (top-left graph in Figure 23 , after the $6^{\text {th }}$ shot is not shown). On the contrary, the LIBS intensity seems to disappear at the $3^{\text {rd }}$ shot from $10 \mathrm{mg} / \mathrm{L}$ sample. A LIBS intensity comparison after the $10^{\text {th }}$ pulse was not possible because the laser pulse had already penetrated through the membrane and a hole was generated. This observation can be explained by the thickness of membrane filter as resulted from the effects of depth profiling on the ion-capture membrane. The $\mathrm{Cu}$ ion in the sample solution is drawn inward on the ion-capture membrane during filtration and captured at a certain depth. It is clear that our laser power, $50 \mathrm{~mJ} /$ pulse, can ablate the Cu-membrane layer by layer. A well prepared calibration curve from other literature[37], using stronger laser power, also showed that the calibration began to taper off at around $10 \mathrm{mg} / \mathrm{L}$ (similar to Figure 22). The authors suggested a linearly regressed calibration curve, simply, for the entire concentration range. The effects of depth profiling on the ion-capture membrane is also proven by the sampling of passive extraction. For the passive extraction, the membrane filter was soaked for 24 hours in $100 \mathrm{mg} / \mathrm{L}$ solution and the LIBS intensity changes of $\mathrm{Cu}$ at $324.75 \mathrm{~nm}$ by the consecutive laser shots are shown in the graph of lower-right in Figure 23. The most intense spectrum was obtained from the first laser shot. None of the ions were drawn physically into membrane during the passive extraction, so they were mostly captured on the surface and gave the strongest LIBS intensity at the first laser shot. It is clear that the membrane captures ions at the deeper layer if the solution is drawn in by suction. As a result, the total ions through the entire thickness should be counted to get the proportional values to determine concentration. A modified calibration curved is made from the integration of 10 laser-shot intensities as in Figure 24 using a $2^{\text {nd }}$ order equation.

\subsection{Analysis of tap water using ion-capture membrane}

Tap water was analyzed by using the ion-capture membrane concentrator and LIBS. The tap water to our lab at Northern Illinois University is supplied throughout the building by copper pipe. There were many studies which showed the copper contamination in the water supply from the pluming. The local government which supplies the tap water to this lab declared that the source of the city water is collected from the active public water supply wells. Inorganic contaminants, such as salt and metals, can be naturally occurring or 


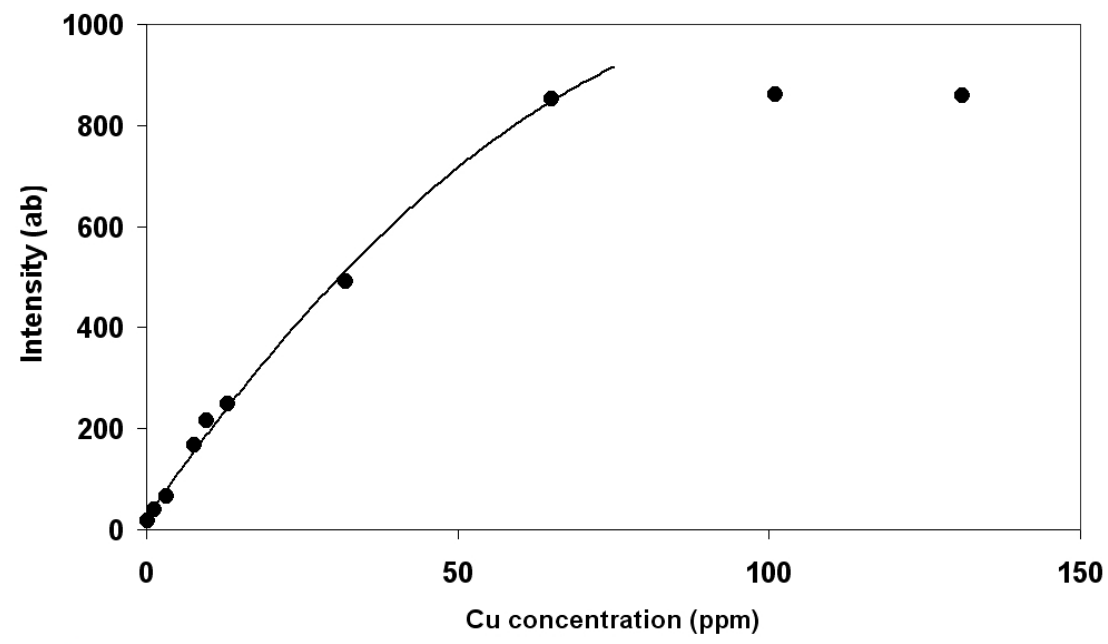

Figure 24. Modified calibration curve made from the integrated intensity of 10 laser shots and $\mathrm{Cu}$ concentration up to $70 \mathrm{mg} / \mathrm{L}$. The obtained curve is $\mathrm{y}=-0.079 \times 2+17.81 \mathrm{x}+23.46$

resulted from urban storm water runoff, industrial, or domestic waste water discharges. The ions of $\mathrm{Ca}, \mathrm{Mg}, \mathrm{Na}, \mathrm{K}$, in the city water are known to be of reasonable concentrations within the EPA regulations. The annual water report from city shows that the concentration of $\mathrm{Cu}$ is $1.3 \mathrm{mg} / \mathrm{L}$, and this amount is expected to maintain reasonably throughout the day and week. To make an illustration on the effects of pluming for copper contamination from the copper pipe, we took water samples during a specific time schedule, early Monday morning and Tuesday evening. Each sample contains $20 \mathrm{~mL}$ of water and filters through an ioncapture membrane. Figure 25 shows the LIBS spectrum of tab water sample captured by the membrane. Copper emissions were identified along with strong peaks of Ca. The concentrations are obtained from the integration of the same number of breakdown shots by using the calibration curve as in Figure 24. In case the integrated intensity is greater than 800 counts, which is around the saturation range, we simply dilute the original sample and measure again. The Tuesday sample shows $\mathrm{Cu}$ concentration in the range of $5-10 \mathrm{mg} / \mathrm{L}$, which is expected due to the large use of water during the active days in the building and the species in the water should be similar to the source water. However, the Monday morning samples show higher concentrations mostly around $100 \mathrm{mg} / \mathrm{L}$ or more. Some water samples show up to $270 \mathrm{mg} / \mathrm{L}$ of copper, especially for hot water pipe line. We can infer for the high concentration of copper on the Monday sample that water remained in the pipes during the weekend and did not move. This result shows that the contamination of copper from the pluming of building is significant and is shown to depend on the retention time of water in the building pipe. 


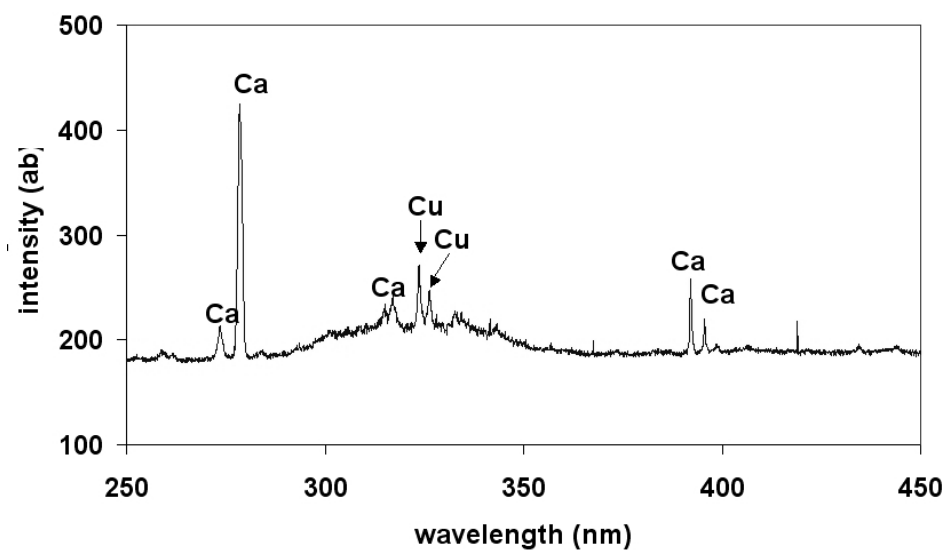

Figure 25. LIBS spectrum of ion captured membrane. The sample solutions are $20 \mathrm{~mL}$ of tap water filtered through membrane filter.

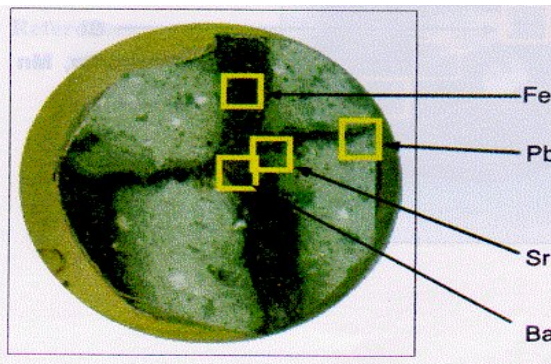

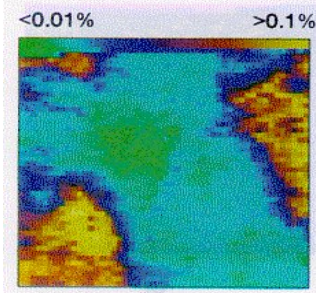

$\mathrm{Ba}$

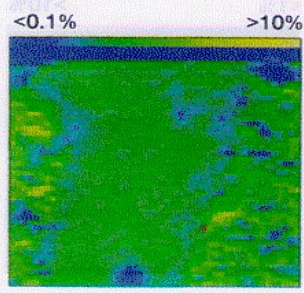

$\mathrm{Fe}$

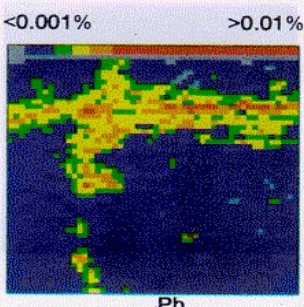

$\mathrm{Pb}$

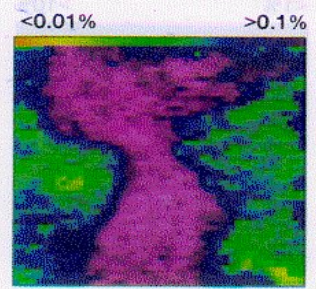

Sr

Figure 26. The elemental distribution of patterns for $\mathrm{Ba}, \mathrm{Pb}, \mathrm{Sr}$, and $\mathrm{Fe}$ in a polished granite rock section. 


\section{d. Ceramic and geology sample application}

Laser induced plasma spectroscopy has been applied to the analysis of element distribution mapping of polished rock sections[40]. The plasma was generated by focusing a frequencydoubled second harmonic $532 \mathrm{~nm}$ Nd:YAG laser on the target under atmospheric conditions. The experimental parameters, such as laser energy, atomic emission line and time profile of the plasma spectrum, were characterized to obtain optimum experimental conditions and estimate the element composition of the target surface. For the element mapping of samples, an X-Y stage was used to move the sample and an element image of 50 $x 50 \mathrm{~mm}$ could be made in $30 \mathrm{~min}$. Using this technique, the element concentration distribution of $\mathrm{Ba}, \mathrm{Cu}, \mathrm{Fe}, \mathrm{Mn}, \mathrm{Pb}, \mathrm{Si}$, and $\mathrm{Sr}$ in polished rock sections were obtained. Quantitative analysis was achieved by analyzing standard rock samples. Calibrated concentration versus plasma intensity was used for the color grading for the mapping of element concentration distribution. The elemental mapping analysis for a granite sample is illustrated in Figure 26. The ore vein within the existing sample was selected to identify the different compositions of ore and surface element distribution. The element distribution differences were represented by color grading, where the upper first line represents the color scale. The region where a lode was crossed during the analysis is rich in $\mathrm{Pb}$ and $\mathrm{Sr}$ but the Ba content is low. Iron does not show differences and is nearly uniformly distributed across the sample.

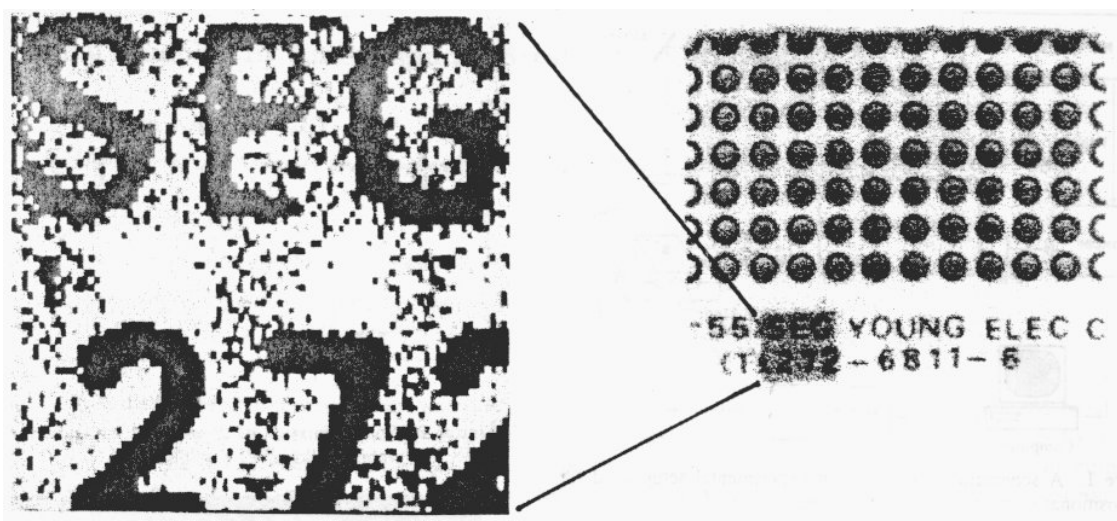

Figure 27. The mapping image of a commercial printed circuit board. Black circle and character on the right circuit board is copper layer for soldering electronic component. The measured values from LIBS constitute pixels on left map.

A sensitive optical technique for compositional mapping of solid surface using LIBS was described[41]. A pulsed Nd:YAG laser with second harmonic module was focused on the solid surface, giving a small ablation area, to produce plasma emission. Copper and magnesium emissions from a standard sample were carefully analyzed and assigned in the wavelength range 500-520 $\mathrm{nm}$. The assigned spectral information was selected to construct an image of $100 \times 100$ pixels by mapping the measured emission intensity values from the analyzed points. The time required for image construction and image sharpness depends on 
the number of laser shots per point of analysis and the number of analyzed points per image. A clear image of a copper conductor pattern from a printed circuit board was generated. In addition, some copper contaminations around the conductor area are clearly visible in the scanning LIBS map. The contaminated copper salt probably resulted from the incomplete washing step during manufacturing that could cause a short circuit in an electronic device. A commercial printed circuit board is shown in the right portion of Figure 27. Circles on the top are patterned copper layer for soldering the electronic components. Characters on the bottom are the same copper layer for product identification. The laserablated area (gray shaded square) is $5 \times 5 \mathrm{~mm}^{2}$. The left portion of Figure 27 is a mapping image of copper corresponding to the gray shaded square. Each 100x100 pixels corresponds to a measured emission intensity value of LIBS on the ablated point.

\section{Conclusion}

The goal of LIBS development is to extend the analytical feasibility of LIBS for detecting organic, inorganic metals and ceramic material for the various applications. The sample types also not limited to the solid and expanded to liquid gas, aerosol, powder, bacteria, and industrial products. Several applications of LIBS were illustrated in this chapter. Detections for metallic components are usually accomplished easily from the measured spectral ranges from ultraviolet $(230 \mathrm{~nm})$ to visible $(700 \mathrm{~nm})$ of the plasma emission. Only a few seconds of measuring time is a great advantage and will be useful for screening and monitoring system for industry and security monitoring. Evaluation of analytical feasibility for detecting and identifying the sample should be decided by analyzing the LIBS spectra of specific components as well as matrix derived from the source of the samples.

\section{Author details}

Taesam Kim and Chhiu-Tsu Lin

Northern Illinois University, Illinois, USA

\section{References}

[1] Jurado-Lopez, A., Lque de Castro M.D. “Laser-Induced Breakdown Spectrometry in the Jewelry Industry. Part I. Determination of the Layer Thickness and Composition of Gold-Plated Pieces" J. Anal.At.Spectrom. 2002, 17, 544-547.

[2] Jurado-Lopez, A., Lque de Castro M.D. “Chemometric Approach to Laser-Induced Breakdown Analysis of Gold Alloys" Appl. Spectrosc. 2003, 57, 349-352.

[3] Sturm V., Peter. L., Noll, R. "Steel Analysis with Laser-Induced Breakdown Spectrometry in the Vacuum Ultraviolet" Appl. Spectrosc. 2000, 54, 1275-1278.

[4] Palanco S., Laserna, J. J. "Full automation of a laser-induced breakdown spectrometer for quality assessment in the steel industry with sample handling, surface preparation and quantitative analysis capabilities" J. Anal. At.Spectrom. 2000, 15, 1321-1327. 
[5] Sattmann, R., Sturm, V., Noll, R. " Laser-induced breakdown spectroscopy of steel samples using multiple Q-switch Nd:YAG laser pulses" J. Appl. Phys., 1995, 28, 21812187.

[6] Kraushaar, M., Noll, R., Schmitz, H. U.“ Slag Analysis with Laser-Induced Breakdown Spectrometry“ Appl. Spectrosc., 2003, 57, 1282-1287.

[7] Mateo, M. P., Cabalin, L. M., Laserna, J. J. “Automated Line-Focused Laser Ablation for Mapping of Inclusions in Stainless Steel" Appl. Spectrosc., 2003, 57, 1461-1467.

[8] Thiem, T. L., Salter, R. H., Gardner, J. A., Lee, Y. I., Sneddon, J. “Quantitative Simultaneous Elemental Determinations in Alloys Using Laser-Induced Breakdown Spectroscopy (LIBS) in an Ultra-High Vacuum" Appl. Spectrosc., 1994, 48, 58-64.

[9] Valdillo, J. M., Grcia, C. C., Palanco, S., Lasena, J. J. “Nanomertic range depth-resolved analysis of coated steels using laser-induced breakdown spectrometry with a $308 \mathrm{~nm}$ collimatied beam" J. Anal. At.Spectrom. 1998, 13, 793-797.

[10] Burgio, L., Clark, R. J., Stratoudaki, T, Doulgeridis, M., Anglos, D. "Pigment Identification in Painted Artworks: A Dual Analysis Approach Employing LaserInduced Breakdown Spectroscopy and Raman Microscopy" Appl. Spectrosc. 2000, 54, 463-469.

[11] Anglos, D., Couris, S., Fotakis, C. "Laser Diagnostics of Painted Artworks: LaserInduced Breakdown Spectroscopy in Pigment Identification" Appl. Spectrosc. 1997, 51, 1025-1030.

[12] Garcia C. C., Corral, M., Vadillo, J. M., Laserna, J. J. “Angle Resolved Laser-Induced Breakdown Spectrometry for Depth Profiling of Coated Materials" Appl. Spectrosc. 2000, 54, 1027-1031.

[13] Marquardt, B. J., Goode, S. R., Angel, S. M. “In Situ Determination of Lead in Paint by Laser-Induced Breakdown Spectroscopy Using a Fiber-Optic Probe" Anal. Chem., 1996, 68, 977-981.

[14] Häkkänen, H. J., Korppi-Tommola, J. E. I. “UV-Laser Plasma Study of Elemental Distributions of Paper Coatings" Appl. Spectrosc., 1995, 49, 1721-1728.

[15] Hidalgo, M., Martin, F., Lasema, J. J. " Laser-Induced Breakdown Spectrometry of Titanium Dioxide Antireflection Coatings in Photovoltaic Cells" Anal. Chem., 1996, 68, 1095-1100.

[16] Moskal, T. M., Hahn, D. W. “ On-Line Sorting of Wood Treated with Chromated Copper Arsenate Using Laser-Induced Breakdown Spectroscopy“ Appl. Spectrosc., 2002, 56, 1337-1344.

[17] Sattmann, R., Moüch, I., Krause, H., Noll, R., Souris, S., Hatziapostolou, A., Mavromanolakis, A., Fotakis, C., Larrauri, E., Miguel, R." Laser-Induced Breakdown Spectroscopy for Polymer Identification "Appl. Spectrosc., 1998, 52, 456-461.

[18] Dixon, P. B., Hahn, D. W. " Feasibility of Detection and Identification of Individual Bioaerosols Using Laser-Induced Breakdown Spectroscopy“ Anal. Chem., 2005, 77, 631638.

[19] Morel, S., Leone, N., Adam, P., Amouroux, J. " LIBS Applications - Detection of bacteria by Time-Resolved Laser-Induced Breakdown Spectroscopy" Appl. Opt., 2003, 42, 61846191. 
[20] Samuels, A. C., Delucia, F. C., McNesby, K. L., Miziolek, A. W. " LIBS Applications Laser-induced breakdown spectroscopy of bacterial spores, molds, pollens, and protein: Initial studies of discrimination potential" Appl. Opt., 2003, 42, 6205-6209.

[21] Knight, A. K., Scherbarth, N. L., Cremers, D. A., Ferris, M. J. " Characterization of LaserInduced Breakdown Spectroscopy (LIBS) for Application to Space Exploration" Appl. Spectrosc., 2000, 54, 331-340.

[22] Yueh, F., Singh, J. P., Zhang, H. "Laser induced Breakdown Spectroscopy, elemental analysis" in encyclopedia of Analytical Chemistry, John Wily \& sons, 2000, pp2066 2087

[23] Sneddon, J., Thiem, T.L., Lee, Y. “Lasers in analytical Atomic Spectroscopy” 1996, VCH publish

[24] Miziolek, A. W., Palleschi, A., Schechter, I. "Laser induced Breakdown Spectroscopy"2006, Cambridge

[25] H.J. Hakkanen, J.E.I. Korppi-tommola, UV-Laser Plasma study of elemental distribution of paper coating. Appl. Spectrosc, v49,(12) 1995,p1721

[26] M. Hidalgo, F. Martin, J. J. Lasema, Laser induced Breakdown spectrometry of titanium dioxide antireflection coating sin photovoltaic cells. Anal. Chem. 1996, 68(7) pp10951100

[27] Demetriosanglos, StelionCouris, Costas Fotakis, Laser diagnostics of painted artworks: Laser-Induces breakdown spectroscopy in pigment identification, Appl. Spectrosco, 81(7),1997 1025-1030

[28] Klaus Loebe, Arnold Uhl, and HartmutLucht, Micro analysis of tool steel and glass with laser-induced breakdown spectroscopy, applie optics 2003, 42(30) 6166-6173

[29] Valery Bulatov, rivieKrasiker, and Israel Schechter, "Study of Matrix effect in laser plasma spectroscopy by combined multifiber spatial and temporal resolutions. Anal chem. 70(24) 1998, pp5302-11

[30] R Gabriele Cristoforetti, Stefano Legnaioli, Vincenzo Palleschi, Azenio Salvetti, Elisabetta Tognoni, Pier Alberto Benedetti, Franco Brioschi and Fabio Ferrario, Quantitative analysis of aluminium alloys by low-energy, high-repetitionrate laserinduced breakdown spectroscopy,J. Anal. At. Spectro. 2006,21 607-702

[31] Prefetti, B. M. Metal Surface Characteristics Affecting Organic Coatings, Federation Series on Coating Technology, FSCT, Blue Bell, PA, 1994.

[32] Weldon, D. G., Carl, B. M. “Determination of Metallic Zinc Content of Inorganic and Organic Zinc-Rich Primers by Differential Scanning Calorimetry" J. coatings technology $1997,69,45-49$.

[33] Stamenkovic, J., Cakic, S., Konstantinovic, S., Stoilkovic, S. "Catalysis of the IsocyanateHydroxyl Reaction by Non-Tin Catalysts in Water borne Two Components Polyurethane Coatings", Working and living environmental protection 2004, 2, 243-250.

[34] Kim T, Nguyen B, Minassian V, Lin C.T Paints and coatings monitored by laser-induced breakdown spectroscopy. J. Coat.Technol. Res. 2007 4:242-255.

[35] Kim T, Specht Z, Vary P, Lin C. T. Spectral fingerprint of bacterial strains by laserinduced breakdown spectroscopy. J. Phys. Chem. 2004 108(17):5477-5482.

[36] Hestekin, J.; Sikdar, S.; Bhattachayya, D.; Bachas, L.; Cullen, L. US Patent 6139742, 2000. 
[37] Schmidt, N.; Goode, S. Appl. Spectrosco., 2002, 56, 370-374.

[38] Dockery, C.; Pender, J.; Goode, S. Appl. Spectrosco., 2005, 59, pp. 252-257.

[39] Kim T, Ricchia M, Lin C. T. Analysis of copper in an aqueous solution by ion- exchange concentrator and laser-iduced breakdown spectroscopy. J. Chin. Chem. Soc. 2010 57(4B):829-835.

[40] Yoon,Y., Kim, T., Chung, K., Lee, K., and Lee, G., “Application of Laser induced Plasma Spectroscopy to the Analysis of Rock Samples", Analyst 1997, 22, pp. 1223-1227

[41] Kim, T., Lin, C., Yoon, Y., “Compositional Mapping by Laser-Induced Breakdown Spectroscopy, J. Phys. Chem. B, 1998, 102 ,pp. 4284-4287 